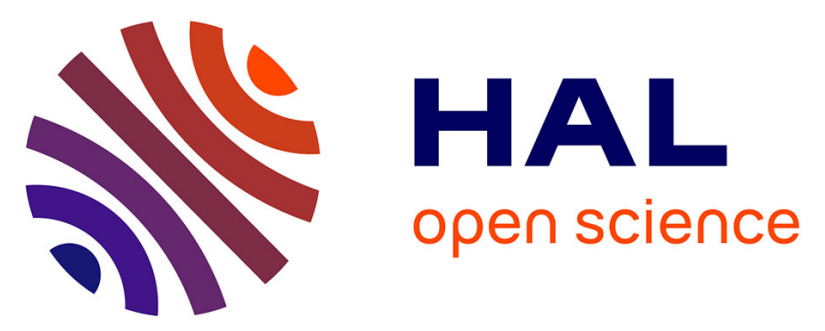

\title{
Experimental determination of electrical conductivity during deformation of melt-bearing olivine aggregates: Implications for electrical anisotropy in the oceanic low velocity zone
}

Luca Caricchi, Fabrice Gaillard, Julian Mecklenburgh, Emmanuel Le Trong

\section{To cite this version:}

Luca Caricchi, Fabrice Gaillard, Julian Mecklenburgh, Emmanuel Le Trong. Experimental determination of electrical conductivity during deformation of melt-bearing olivine aggregates: Implications for electrical anisotropy in the oceanic low velocity zone. Earth and Planetary Science Letters, 2011, 302, pp.81-94. 10.1016/j.epsl.2010.11.041 . insu-00556767

\section{HAL Id: insu-00556767 https://hal-insu.archives-ouvertes.fr/insu-00556767}

Submitted on 18 Jan 2011

HAL is a multi-disciplinary open access archive for the deposit and dissemination of scientific research documents, whether they are published or not. The documents may come from teaching and research institutions in France or abroad, or from public or private research centers.
L'archive ouverte pluridisciplinaire HAL, est destinée au dépôt et à la diffusion de documents scientifiques de niveau recherche, publiés ou non, émanant des établissements d'enseignement et de recherche français ou étrangers, des laboratoires publics ou privés. 


\section{Experimental determination of electrical conductivity during deformation of melt-bearing olivine aggregates: implications for electrical anisotropy in the oceanic low velocity zone}

Luca Caricchi $^{1,2}$, Fabrice Gaillard ${ }^{1}$, Julian Mecklenburgh ${ }^{3}$, Emmanuel Le Trong ${ }^{1}$

1. Centre National de la Recherche Scientifique (CNRS), Institut National des Sciences de l'Univers (INSU), Université d'Orléans, Institut des Sciences de la Terre d'Orléans, UMR 6113, Campus Géosciences, 1A, Rue de la Férollerie, 41071 Orléans cedex 2, France.

2. Department of Earth Sciences, University of Bristol, Wills Memorial Building, Queens's Road, Bristol BS8 1RJ, United Kingdom.

3. School of Earth, Atmospheric and Environmental Sciences, Williamson Building, the University of Manchester, Manchester M13 9PL, United Kingdom.

Corresponding author: Luca Caricchi, e-mail: l.caricchi@bristol.ac.uk 


\section{Abstract}

A novel experimental setup was used to measure in-situ variations of electrical conductivity (EC) during deformation in torsion (simple shear) at $300 \mathrm{MPa}$ confining pressure and temperatures between 873 and $1473 \mathrm{~K}$. This setup is designed to test if deformation of partially molten systems can produce electrical anisotropy. The motivation for this study comes from the observation that the Lithosphere-Asthenosphere Boundary (LAB) at mid ocean ridges and in particular at the East Pacific Rise is strongly electrically anisotropic.

In an initial set of calibration experiments, the variation of EC with temperature (8731473K) was determined for Carrara marble, Åheim dunite and basalt-bearing olivine aggregates. EC was then monitored during deformation experiments at $1473 \mathrm{~K}$ and measured in the frequency range between $6 \mathrm{MHz}$ and $1 \mathrm{~Hz}$. The electrical response of the different materials tested as a function of frequency, changes significantly depending on the presence, absence, proportion and distribution of melt contained in the specimen. Melt-free samples show a single conduction mechanism whereas melt-bearing samples display two conduction mechanisms linked in series, reflecting the contribution of isolated and connected melt. Impedance was measured along the sample radius, in a direction parallel to the shear gradient inherent in torsion experiments. During the tests, increasing values of the impedance measured suggest that the long range melt connectivity decreases radially, and melt drains from low to high shear stress regions. The conductivity, calculated from impedance measurements, is low and comparable to values measured along Mid-ocean ridges. We suggest that electrical anisotropy of the LAB reflects an alternation of melt-enriched and melt-depleted channels elongated in the 
spreading direction possibly induced by spreading velocity gradients along the ridge. This implies that the observed electrical anisotropy reveals larger scale processes than straininduced generation of crystallographic preferred orientations. Such large-scale processes could influence the distribution of seamounts and chemical variations of mid-ocean ridge basalts.

\section{Introduction}

Magneto-telluric investigations at the East Pacific Rise (EPR), a fast spreading mid-ocean ridge (MOR), have shown that the LAB is characterized by high electrical conductivity (EC) in the direction of spreading $\left(10^{-1} \mathrm{~S} \mathrm{~m}^{-1}\right)$, and lower EC parallel to the ridge $\left(10^{-2.5}\right.$ $\mathrm{Sm}^{-1}$; Evans et al., 2005; Baba et al., 2006). To explain this characteristic, two main hypotheses have been proposed: a) the lattice preferred orientation (LPO) of olivine (the main constituent of the upper mantle), but the experiments of Yoshino et al. (2006) shown this explanation to be very unlikely b) the presence of a small amount of melt anisotropically distributed (Yoshino et al., 2006; Gaillard et al., 2008). In this second scenario, the melt-phase is required to be highly connected in the direction of spreading and arranged with reduced connectivity in the ridge parallel direction in order to account for the observed anisotropy of the LAB (Evans, 2008; Gaillard et al., 2008). At present, deformation of partially molten rocks have been shown to affect grain boundary wetting (Zimmerman et al., 1999; Hier-Majumder et al., 2004; Holtzman et al., 2003), but the anisotropy this would produce in the inferred flow regime of the LAB cannot explain the electrical anisotropy observed. Recently, Takei and Holtzman (2009) showed that melt redistribution can be triggered by shear stress gradients. The analysis of a global dataset of spreading rates reveals that the spreading velocity, in the ridge parallel direction, in 
mid ocean ridge sectors contained between transform faults is not constant (Muller et al., 2008), which may result from shear stress gradients in the LAB (Turcotte and Schubert, 2002). Here, we test the effect of simple shear deformation, in presence of a stress gradient, on the variation of electrical conductivity (EC) of partially molten rocks by performing the first in-situ EC measurements during deformation of melt-bearing olivine aggregates. Alternating current measurements of electrical conductivity at variable frequencies are highly suited to characterize the in-situ melt topology in a partially molten system, since the electrical conductivity of partially molten rocks is strongly dependent on the geometrical distribution of the melt (Roberts and Tyburczy, 1999). Considering basalt-bearing olivine aggregates, if the melt (in our case Kilauea basalt at $1473 \mathrm{~K}$ with EC $\sim 0.8 \mathrm{Sm}^{-1}$, see Pommier et al., 2010) forms a fully interconnected path along wetted grain boundaries and in three grain edges, olivine and basaltic liquid constitute independent parallel circuits, and the bulk EC is about 1 to 2 orders of magnitude higher than that of pure olivine $\left(\sim 0.8 \cdot 10^{-3} \mathrm{Sm}^{-1}\right.$ at $1473 \mathrm{~K}$, see Constable and Duba, 1990; Roberts and Tyburczy, 1999; Gaillard and Marziano, 2005). Whereas, if the melt is only connected over short length scales (ca. grain size) being in triple junctions and isolated melt pockets, the two phases are arranged in series, and the EC will approach that of olivine (Roberts and Tyburczy, 1999; ten Grotenhuis et al., 2005).

\section{Experimental and analytical techniques}

\subsection{Sample preparation}

Experiments were performed on Carrara marble, Åheim dunite and San Carlos olivine aggregates containing 4 (4B) and 8 wt.\% (8B) basaltic melt (STV 315; see Pichavant and Macdonald, 2007). As STV315 is nearly saturated in olivine at 1473K (temperature at 
which most of the deformation experiments were performed) very little reaction occurred between the olivine and the melt during the experiments. Therefore variation in temperature only results in very small changes in melt fraction. Cylindrical samples of 10 mm external diameter were drilled from natural specimens of Carrara marble and Åheim dunite. Basalt bearing olivine aggregates were synthesised before measuring electrical conductivity, but in one experiment the measurements were performed during sintering. Grains of San Carlos olivine were reduced in size, using an agate sphere-mill and agate mortar, down to an average size of 20-40 mm. Fine-grained basaltic glass $(5-10 \mathrm{~mm})$ and powdered olivine were thoroughly mixed and hot-isostatically pressed (HIP) in a Paterson apparatus (Paterson and Olgaard, 2000) at $300 \mathrm{MPa}$ and $1473 \mathrm{~K}$ for 6 hours. The sample was isolated from the contact with the iron jacket and the ceramic pistons using nickel foil. NiO (a greenish powder) was visible between the sample surface and the residual nickel foil at the end of the syntheses, indicating that the oxygen fugacity was buffered near to the $\mathrm{Ni}-\mathrm{NiO}$ reaction. Cylindrical samples of $10 \mathrm{~mm}$ in diameter and 5-9 $\mathrm{mm}$ in length were cored from the hot-pressed material. The nickel disks initially present between the starting powders and the ceramic pistons, on both ends of the samples, were removed, and finally, the ends of the samples were ground to obtain parallel ends to within $0.001 \mathrm{~mm}$. A $4 \mathrm{~mm}$ hole was subsequently drilled in the centre of the cylindrical specimens, in order to place a central electrode for impedance measurements.

\subsection{Electrical conductivity measurements}

The conventional experimental assembly, used to measure rheological properties in an internally heated Paterson-type deformation apparatus (Paterson and Olgaard, 2000), was modified to measure electrical properties both in static conditions and during deformation 
experiments at high pressure and temperature (Fig. 1). While all the details about the Paterson apparatus can be found in Paterson and Olgaard (2000), we detail below the modifications applied to the experimental assembly to measure EC.

Nickel cylinders $4 \mathrm{~mm}$ in diameter and the same length of the samples were placed in the core of the specimens and used as the central electrode (Fig.1). A nickel foil was placed on the external surface of the samples and it was used as the second electrode. The samples were placed in the centre of a symmetric assembly composed, on each side, of cylindrical ceramic pistons. The top ceramic piston (both PSZ and alumina) had a central hole of $2 \mathrm{~mm}$ in diameter (Fig.1). The hole in the ceramic piston placed on top of the sample was enlarged to $4 \mathrm{~mm}$ using a diamond drill bit and filled with a stainless steel cylinder of $3 \mathrm{~mm}$ in length. The thermocouple was passed from outside the vessel and put in contact with this stainless steel insert (i.e. $3 \mathrm{~mm}$ away from the top of the sample; Fig. 1). The steel served to prevent the extrusion of the sample and the nickel central-electrode (pressurized by the confining pressure) through the thermocouple hole (at ambient pressure) and to bridge the contact between the central-electrode, placed in the centre of the sample, and the shield of the thermocouple that was connected to the impedance spectrometer (Mecklenburgh et al., 2003). Temperature in the Paterson apparatus was measured with a N-type (nicrosil-nisil) thermocouple. The temperature profile along the furnace was previously calibrated and a variation of about $5 \mathrm{~K}$ was measured over a 30 $\mathrm{mm}$ length around the sample position. Due to the length of the samples (4-9 $\mathrm{mm}$ ), considerably smaller than the hot spot of the furnace, the temperature difference in the sample will be ca. $1-2 \mathrm{~K}$. 
The sample and the ceramics were inserted inside an iron jacket, which isolated the ceramics and the specimens form the argon gas that is used as confining pressure medium. The electrical conductivity (EC) was measured radially between the central nickel cylinder and the nickel foil surrounding the sample, which is in tight contact with the external iron jacket (Fig. 1).

The temperature was kept constant for at least 30 minutes before starting the impedance measurements. The electrical response of the samples was measured at frequencies between $6 \mathrm{MHz}$ and $1 \mathrm{~Hz}$ using a 1260 Impedance Gain Phase Analyzer, (Schlumberger Co.). The electrical conductivity $(s)$ was obtained from the resistance $(R)$ using the following relationship (Gaillard, 2004; Pommier et al., 2008):

$$
\sigma=\frac{\log _{e}\left[\frac{d_{\text {ext }}}{d_{\text {int }}}\right]}{2 \pi L} \frac{1}{R}
$$

where $L$ is the sample length $d_{\text {ext }}$ is the external diameter of the sample and $d_{\text {int }}$ is the diameter of the inner electrode. The validity of Equation 2 was verified by Pommier et al. (2010).

In the present configuration, EC is measured along the sample radius along which in torsion deformation, there is a gradient in shear stress, which varies from zero on the axis of rotation of the sample to a maximum at the outer surface of the sample. Figure $1 \mathrm{~B}$ shows the radial shear stress variation for a material with a stress exponent of 3 (Paterson and Olgaard, 2000). The reproducibility of resistivity, estimated by repeated measurements at constant experimental conditions was about 5\%. For olivine-basalt aggregates the variations were in some case larger, probably because of some minor differences in melt content and distribution, which, as it will be explained below, are fundamentally control the resistivity of the material. 


\subsection{Frequency dependence of EC}

The frequency-dependent electrical response of semi-conductive material, such as rocks and partially molten systems, can be conveniently represented in the Nyquist-plane as they have complexed impedance (e.g. (Roberts and Tyburczy, 1999; Pommier et al., 2008) since the impedance is the sum of a real in-phase $\left(Z^{I}\right)$ and an imaginary out-ofphase $\left(Z^{I I}\right)$ impedance $\left(Z=Z^{I}+j Z^{I I}\right.$ where $j=\sqrt{-1}$ ). In the Nyquest plane, if only one conduction path is active, the electrical response as function of frequency is an arc where the intercept with the $\mathrm{Z}^{\mathrm{I}}$-axis is the resistance and can be represented by the equivalent circuit of a resistor and capacitor in parallel (see Fig 2, 3). Two or more arcs present in different frequency-ranges indicate that two or more conduction mechanisms are simultaneously active in series and the bulk resistance is the sum of the high frequency and low frequency resistance (Roberts and Tyburczy, 1999; see Fig 3). In this case the electrical response can be modelled with an equivalent circuit consisting of a serial array of resistors and capacitors in parallel, each with a different frequency response. In the rest of the paper this sort of presentation will be used to relate the observed electrical response to the geometrical distribution of melt during static and deformation experiments.

\subsection{Analytical techniques and imaging}

Chemical analyses of minerals and glass were performed using a Cameca SX50 electron microprobe (EMP) at the Bureau de Recherche Géologiques et Minières (BRGM) in Orleans (France). The analytical conditions used for minerals were $15 \mathrm{keV}$ acceleration voltage, $20 \mathrm{nA}$ beam current and 1-2mm beam diameter. To analyze glasses the beam current was decreased to $5 \mathrm{nA}$ and the beam diameter increased to $10-20 \mathrm{~mm}$ depending on the size of the glass inclusions between the minerals. Back-scattered electron images 
were collected using a JEOL-JXA-8200 electron microprobe at the department of Earth Sciences of ETH Zurich (Switzerland) and a Hitachi S-3500N at the Department of Earth Sciences of the University of Bristol (United Kingdom).

\section{Results}

A first set of experiments were performed on Carrara marble, Åheim dunite and olivine plus basalt samples to test the reliability of the experimental assembly and to measure the variation of the electrical response of the samples as a function of temperature and time. At each temperature step, the measurements were repeated 3-5 for a total of 20 to 60 minutes until a constant value of resistance was obtained. All the experiments were performed at a constant confining pressure of $300 \mathrm{MPa}$. After the last measurement the experiments was terminated decreasing the temperature with a rate of about $60 \mathrm{~K} / \mathrm{min}$.

\subsection{Carrara marble}

Preliminary tests using the described configuration were performed on Carrara marble specimens for which an impedance dataset exists (Heege and Renner, 2007). The sample was kept at $873 \mathrm{~K}$ for 2 hours before a stable value of impedance was achieved. At this temperature a single impedance arc was observed and the stable values of resistivity was about $1650 \mathrm{~W} \cdot \mathrm{m}$.

\section{2 Åheim dunite}

Energy dispersive $\mathrm{x}$-ray spectroscopy (EDS) performed in a scanning electron microscope in Bristol, and observations using the optical microscope, revealed that the Åheim sample used for experiments is mainly composed of olivine with minor orthopyroxene, clinopyroxene and phlogopite. Electrical impedance measurements were 
performed during a heating and cooling cycle to check for eventual variations of the geometry and the physical properties of the sample. The electrical signal was characterized by the presence of a high frequency (Hf) and a low frequency (Lf) arcs in the Nyquist-plane between temperatures of 1273 and 1473 K (Fig. 2). These arcs are not perfectly semicircular they are slightly squashed parallel to the x-axis. This kind of impedance arc can be represented with an equivalent circuit of a resistor and a constant phase element in parallel. This response is thought to be a result of a distribution of timeconstants along the surface of the electrodes or perpendicular to the surface. This distribution of time constants could either be an inherent material property or due to roughness of the sample electrode interface (Orazem and Tribollet, 2008). Electrical conductivity increases with temperature, however, the activation energies for bulk (sum of Hf and Lf conductivity) and Hf conductivity are different (Fig. 2). In particular, the activation energy for the $\mathrm{Hf}$ mechanism decreases significantly for temperature higher than $1373 \mathrm{~K}$. Observations using an optical microscope showed that phlogopite reacted during experiments to produce a melt phase.

\subsection{Impedance measurements during sintering of a basalt bearing aggregate}

The conductivity was measured during the sintering of a San Carlos olivine aggregate containing $4 \mathrm{wt} . \%$ basalt (4B). Only one arc at low frequency was visible during the first 1 hour at $1473 \mathrm{~K}$ in the impedance scan, while at constant temperature a second lowfrequency arc appeared and grew in diameter during the rest of the experiment (6 hours; Fig. 3). The sample is very conductive at the beginning of the experiment, while its conductivity decreases significantly after the first hour of sintering (Fig. 3). The Hf arc enlarge only slightly between the first hour and the end of the experiment while the main 
increase of impedance was related to the significant growth of the Lf arc. As with the Åheim dunite the impedance arcs are not perfectly semicircular probably due to either material properties of the sample or the sample electrode surface creating a distribution of time-constants.

\subsection{Basalt-olivine aggregates}

After sintering, the variation of EC as a function of temperature was determined on olivine aggregates containing 4 and $8 \mathrm{wt} . \%$ basalt (8B). The impedance was measured for both sample $4 \mathrm{~B}$ and $8 \mathrm{~B}$ every $50 \mathrm{~K}$ between 1273 and $1473 \mathrm{~K}$ and two partially overlapping arcs were always observed. The diameters of the $\mathrm{Hf}$ and the Lf arcs increase with decreasing temperature (i.e. the EC of both conduction mechanisms decreases with temperature) and both the bulk and the Hf-EC is always higher for the sample with the highest amount of basalt (Fig. 4). The activation energies (Ea) of 4B and 8B for the Hf mechanism are comparable (195 \pm 10 and $221 \pm 10 \mathrm{kJmol}^{-1}$ respectively) while the Ea related to the bulk conductivity are quite different $\left(134 \pm 10\right.$ for $4 \mathrm{~B}$ and $207 \pm 10 \mathrm{kJmol}^{-1}$ for $8 \mathrm{~B})$. Reproducibility tests were performed at $1473 \mathrm{~K}$ on samples produced in different syntheses: for $4 \mathrm{~B}$ the second measurements gave $2.1 \cdot 10^{-3} \mathrm{Sm}^{-1}$ instead of $1.2 \cdot 10^{-3} \mathrm{Sm}^{-1}$, for $8 \mathrm{~B} 1.3 \cdot 10^{-2} \mathrm{~S} \cdot \mathrm{m}^{-1}$ instead of $1.0 \cdot 10^{-2} \mathrm{Sm}^{-1}$ (Table 1 online material). It is worth pointing out that the rate of change of conductivity with melt fraction at $4 \%$ melt will be much greater than at $8 \%$ therefore it would be expected that small variations in melt fraction between two samples with $\sim 4 \%$ melt will show a much larger variability in conductivity than $8 \%$ melt samples with the same melt fraction difference.

\subsection{Simple shear deformation}


Deformation experiments were performed applying a constant strain rate and carrying out strain rate stepping tests (e.g Paterson and Olgaard, 2000). The torque was continuously recorded and the corresponding shear stress was calculated using the equations reported in Paterson and Olgaard (2000) for hollow specimens with a cylindrical core of Nickel (the electrode). The part of the measured torque supported by the Ni inner electrode, at the conditions of deformation (1473K), is likely to be small because (i) the Ni will be weak at 1473K (Frost and Ashby, 1982) and (ii) the strain rate is lower in the inner part of the sample. Using published flow-laws for Ni (Frost and Ashby, 1982) the torque supported by the Ni electrode, at $1473 \mathrm{~K}$ for a sample strain rate of $1 \times 10^{-5} \mathrm{~s}^{-1}$, is calculated to be $0.03 \mathrm{Nm}$ which is within the resolution of the torque gauge.

A first stage of elastic deformation was followed by yielding (and strain hardening) and finally sample-flow at constant stress or shear weakening in 8B (Fig. 5A). A stress exponent of $3 \pm 0.5$ was obtained by strain rate stepping tests testifying deformation in dislocation creep or dislocation creep accommodated grain boundary sliding field (Hirth and Kohlstedt, 1995; Hirth and Kohlstedt, 2003). Deformation in simple-shear resulted in the enlargement of both the $\mathrm{Hf}$ and Lf arc; however, the increase in diameter of the Lf arc was much greater (Fig. 5C, D). The decrease of bulk EC was about 1 order of magnitude for sample $8 \mathrm{~B}$ for a total applied gamma of 0.45 (Fig. 5A, C), while the EC associated to the Hf conduction mechanism decreases from about 0.025 to $0.01 \mathrm{~S} \cdot \mathrm{m}^{-1}$. The decrease of bulk EC occurred mainly during at the beginning of the deformation (Fig. 5A). To measure the effect of temperature on the decrease of EC associated with deformation, the temperature was increased from 1373 up to $1473 \mathrm{~K}$ during a torsion experiment at constant strain rate. Figure 5B shows that the rate of decrease of EC increases with this 
temperature step. At the end of the experiments presented in Figure 5 the deformation was stopped and pressure and temperature were kept constant. Stress release produced an increase in bulk EC that was however much slower and less significant than the drop associated to deformation. The variation of the Hf conductivity produced by the release of stress was even less significant than that observed for bulk EC.

\subsection{Microstructural observations of deformed basalt-olivine aggregates}

In an attempt to characterise the 3D microstructure of the samples two sections were cut from the deformed samples (i) the tangential plane perpendicular to the shear plane containing the shear direction (perpendicular to conductivity measurement) and (ii) the diametric plane perpendicular to the shear direction (parallel to the conductivity measurement). Optical analyses of samples after deformation, showed a colour change from pale to dark green from the centre of the specimens toward the outer diameter (Fig. 6A). Chemical analyses performed with an EMP excluded the possibility of this colour change to be associated to changes in the olivine chemistry. To characterize the melt distribution back-scattered electron images (BSE) were collected using an electron microprobe, for both the tangential and diametric sections. Due to the limited back-scatter contrast between basaltic glass and olivine crystals, it was not possible to automatically separate the olivine and glass on the images. Consequently large images were printed and the glass pockets were traced manually and highlighted (Figure 6). After tracing the images were digitalized and converted into binary images (black=olivine; white=glass). Images of diametral and tangential sections of sample 8B were analysed using Image software (Abramoff et al., 2004). The average grey level was measured for slices of the image every micron and converted into glass percentage (Fig.6). The amount of glass was 
additionally measured in intervals of different bin sizes (50-100-200 $\mu \mathrm{m})$ along the sections to visualise better the distribution of melt content along the profiles (Fig. 6). Figure 6A shows a general increase of glass content from the inner portion of the sample, deformed at lower strain and applied stress, to the outer portions deformed to a strain of about 0.5 and where the stress was the highest (Fig. 1B). The data show, for all the different bin sizes, an increase of about 3\% glass from the centre to the external portion of the sample.

Figure $6 \mathrm{~B}$ presents the analysis performed on a section cut parallel to the sample axis close to the outer diameter of the specimen (tangential section). The average glass content is higher than in the diametral section and an alternation of melt-enriched and meltdepleted portions of the sample is present (Fig. 6B). In general the average melt content determined by image analyses were always lower than the amount of glass that was used for the basalt-olivine aggregate. This was most probably a consequence of the relatively slow rate of temperature decrease at the end of the experiments, which resulted in olivine crystallization. This is confirmed by the presence of small euhedral olivine grains with distinctive composition (FeO 11wt.\%) compared to the San Carlos grains (FeO 8wt.\%). Analyses of the glass after the experiments did not reveal significant variation in composition.

\section{Discussion}

The tests performed on Carrara marble and Åheim dunite specimens confirmed that the experimental setup used in this study is reliable and gives consistent results. The electrical response as a function of frequency and the resistivity of the Carrara marble sample are in agreement with the previously reported data on carbonates (Heege and 
Renner, 2007). In the Åheim dunite sample a variation of the impedance spectra (Fig. 2A), and a significant change of the electrical conductivity associated to the $\mathrm{Hf}$ mechanism were observed at temperatures between 1323 and $1373 \mathrm{~K}$ (Fig. 2B). This modification of the high-frequency electrical-response of the sample could be associated to the onset of phlogopite breakdown (forming melt) resulting in a switch of the conduction mechanism from grain interior in absence of melt, to conductivity associated to short-scale melt connectivity at higher temperature (Roberts and Tyburczy, 1994). The temperature range of this transition is in agreement with data on fluid-absent melting of phlogopite (Wendlandt and Eggler, 1980).

4.1 Electrical response of basalt-bearing olivine aggregates: deciphering connected vs. non-connected melt in absence of deformation

Two impedance arcs were always observed in our experiments on melt bearing samples (Figs. 2-5). The size of both arcs is dependent on melt fraction, connectivity and tortuosity, yet during deformation and sintering at constant melt fraction the size of arcs varied caused by changes in connectivity. Multiple conduction mechanisms, as deduced from multiple impedance arcs, are consistent with the theory for EC of partially molten systems (Roberts and Tyburczy, 1999), but most experimental studies have failed to clearly measure more than one impedance arc for partially molten rocks (Roberts and Tyburczy, 1994, 1999; Maumus et al., 2005; ten Grotenhuis et al., 2005). In these studies, mostly performed at atmospheric pressure, the high frequency arc has been interpreted as the bulk impedance of the sample while sample-electrode polarization obliterated the second arc (Roberts and Tyburczy, 1999; ten Grotenhuis et al., 2005). For the highpressure experiments described in Maumus et al. (2005) (i.e. solid pressure medium), 
sample-electrode polarization also dominated the low frequency part of their measurements. These electrode interferences were not observed using our experimental setup probably because of the applied confining pressure and the relatively large sample size. Given that for two or more conduction mechanism that are electrically in series, the bulk low-frequency impedance ( $\left.\mathrm{R}_{\text {bulk }}\right)$ is given by the sum of the in-phase impedances of the different conduction mechanisms (Roberts and Tyburczy, 1994, 1999), R $\mathrm{R}_{\text {bulk }}$ measured in our static experiments, for partially molten samples, is higher than previously reported (Roberts and Tyburczy, 1999; Maumus et al., 2005; ten Grotenhuis et al., 2005). Interestingly, the EC associated to the high frequency arc in our experiments, is comparable to the conductivity measured in previous study at $\mathrm{Hf}$ and reported as bulk conductivity (Figs. 5; Roberts and Tyburczy, 1999; Maumus et al., 2005; ten Grotenhuis et al., 2005).

Following previous work (Sato and Ida, 1984; Roberts and Tyburczy, 1994) multiple arcs must indicate that different conduction mechanisms operate at different length-scale in the material and that the electrical relaxation times of each conduction mechanism are sufficiently different (resulting in the different frequency response). As an example in polycrystalline aggregates the high frequency arc corresponds to grain interior conduction while a second arc to lower frequencies is associated to grain boundary conduction. The total impedance of this material is therefore given by the sum of the in-phase impedance of each mechanism (Roberts and Tyburczy, 1994). In melt bearing aggregates, the high frequency arc, associated to grain interior conduction, is modified by the presence of melt pockets while the low frequency arc gives information on the degree of long range connectivity of melt (Roberts and Tyburczy, 1994). 
Electrical conductivity (or impedance) of two-phase aggregates in which the constituents have different electrical properties, can be recalculated as function of the relative volumetric proportions, the EC of the single phases, and their geometrical arrangement using effective medium theory (e.g. Hashin and Shtrikman, 1962).

The two end member configurations for the electrical conductivity of an olivine plus melt aggregate are (i) melt isolated in pockets:

$\sigma_{p o c k e t s}=\sigma_{o l}+x_{m} \cdot\left(\frac{1}{\sigma_{m}-\sigma_{o l}}+\frac{1-x_{m}}{3 \cdot \sigma_{o l}}\right)^{-1}$

And (ii) melt fully connected along grain boundaries:

$\sigma_{\text {connected }}=\sigma_{m}+\left(1-x_{m}\right) \cdot\left(\frac{1}{\sigma_{o l}-\sigma_{m}}+\frac{x_{m}}{3 \cdot \sigma_{m}}\right)^{-1}$

Where $s_{o l}$ is the conductivity of olivine crystals, $x_{m}$ is the melt fraction and $s_{m}$ is the conductivity of melt and the conductivity of the melt phase is significantly higher than that of olivine (Constable and Duba, 1990; Pommier et al., 2010). Considering that the Hf arc give information on the melt distribution at the scale of few grains, while the lower frequency arc carries information on the bulk melt distribution. Let us apply the mixing models to three melt bearing olivine-aggregate systems in which the melt is arranged in different geometries but it is present in the same volumetric fraction (see Fig 3B,C,D): i) all melt is connected in the entire volume of the sample (Fig. 3B) ii) all the melt is isolated in pockets (Fig. 3C), iii) most of the melt phase is isolated in pockets and a minor volume fraction is connected in the entire volume of the sample (Fig. 3D). In the first configuration, the electrical response of the sample produces a single arc since the melt is connected in parallel with the olivine (Fig.3 B). In the second arrangement, the melt that is isolated in pockets wetting few grains produce the Hf arc (its size increases with the 
amount of non-connected melt), while the impedance of the Lf arc is due to bulk sample properties and it is proportional to $1 / s_{\text {pocket }}$ (Fig. 3C). Finally, the third melt-olivine distribution should produce an $\mathrm{Hf}$ response broadly similar to the configurations 3C, but it would give lower Lf impedance because of the presence of a minor amount of melt connected at long-scale. The Lf impedance is directly proportional to $1 / s_{\text {connected }}$ and to the relative volume of sample in which the melt is connected at long scale (Fig. 3D). Mixing models (e.g. Archie's law) can be used to recalculate the relative proportions of sample characterized by long and short-scale melt connectivity:

$\sigma_{L f}=\left(\sigma_{\text {connected }}\right)^{V X m_{\text {commected }}} \cdot\left(\sigma_{\text {pockets }}\right)^{\left(1-V X m_{\text {commected }}\right)}$

Where $\sigma_{L f}$ is the Lf conductivity and $V X m_{\text {connected }}$ is the volume fraction of sample in which the melt is connected at long scale. In the following, we use these simple mixing models to quantify the distribution of melt in samples in static conditions and to characterise the variation of melt distribution associated to deformation.

To recalculate the volumetric fractions from the weight fraction of basalt bearing olivine aggregates, the density model for silicate melt proposed by Lange and co-workers was used (Lange and Carmichael, 1987; Lange, 1996, 1997). A density of $3.3 \mathrm{~g} / \mathrm{cm}^{3}$ was assumed for olivine. The values reported by Pommier et al. (2010) for Kilauea basalt and Constable and Duba (1990) were used for the conductivity of the basalt and olivine respectively. It is useful here to recall of the equilibrium distribution of melt and how it may detract from this equilibrium configuration. The equilibrium melt distribution is controlled by the dihedral angle which for olivine plus basaltic melt is $\sim 30^{\circ}$, this will result in the melt being concentrated at three grain edges and triple junctions (e.g. Holness, 2006; Kohlstedt, 2002). The single arc observed in the first phase of the 
sintering experiment (Fig. 3A) is in agreement with a fully connected melt network between the electrodes (Fig. 7, Table 1 online material). The high EC recorded in this first phase of the test, was probably due to the melt being distributed evenly throughout the sample as thick films coating all grain boundaries resulting in a high connectivity of the basaltic melt. The growth of the second arc was most likely related to the attainment of a more equilibrated texture in which the melt was distributed in isolated melt pockets in triple junctions of the olivine grains, and a minor melt fraction in grain boundaries and along grain edges forming a fully connected network between the electrodes (Fig. 3D). Noticeably, the bulk EC for the two arcs connected in series was almost one order of magnitude lower than that at the beginning of the sintering (Figs. 3, 7, Table 1 online material).

Figure 4A shows the different electrical responses of sample $4 \mathrm{~B}$ and $8 \mathrm{~B}$. The main difference is the size of both the high and low frequency arcs and consequently the impedance associated to the different conduction mechanisms. The increasing amount of basaltic melt from $4 \mathrm{~B}$ to $8 \mathrm{~B}$ results in an increase of long range melt connectivity and a consequent decrease of the volume of sample in which isolated melt pockets are present. This translated in a strong decrease of the impedance associated to the Lf arc from $4 \mathrm{~B}$ to 8B and also a decrease of the Hf-arc size.

In summary, we confirm that the Hf impedance arc gives information on melt distribution at the scale of few grains while the Lf impedance arc gives the melt distribution in the entire sample volume. On this bases, the variation of electrical response with deformation can be used to track the evolution of melt distribution during deformation.

4.2 Effect of deformation on the electrical response of basalt-bearing olivine aggregates 
Deformation in simple shear resulted in a decrease of the bulk EC (Figs. 5, 7). Impedance spectroscopy measurements and the micro-structural analyses of the samples clearly indicate that stress/strain-induced melt redistribution is responsible for the observed significant decrease of EC with deformation (Fig. 6A). Figure 5 C, D and Figure 7 show that the decrease of bulk conductivity was mostly related to a strong increase of resistivity of the low frequency arc. The high frequency arc, associated to the short scale melt connectivity, enlarged only slightly with deformation. The marked growth of the Lf arc with deformation indicates a decrease of the melt fraction that was continuously connected between the electrodes (i.e. along the sample radius; Fig. 1). Such an interruption of large-scale melt connectivity increases the volume of sample in which the liquid was only connected at short scale, and consequently increases the relative contribution of the Hf arc. Using a geometrical model (Archie's law; Watanabe and Kurita, 1993; ten Grotenhuis et al., 2005) it is possible to recalculate the relative proportions of sample in which the melt is connected at long-range, using the EC associated to the low frequency arc. For sample $8 \mathrm{~B}$, these calculations give about 80 vol.\% of sample in which the melt was connected between the electrodes. This proportion decreases to 0 vol.\% for a strain gamma equal to 0.45 (Fig. 7), reaching a bulk EC value in agreement with that measured by Constable and Duba (1990) for pure olivine aggregates. For sample 4B the volumetric portion of sample in which the melt is connected between the electrodes is 50 vol.\% before deformation decreasing to 10 vol.\% after a total strain gamma of 0.1 (Fig. 7). The experiment performed on sample 4B at constant strain rate and increasing temperature from 1373 to $1473 \mathrm{~K}$ supported the hypothesis that the observed variations of EC are associated with melt migration and 
rearrangement. The decrease of conductivity associated to deformation was directly proportional to temperature (Fig. 5B) and between 1373 and $1473 \mathrm{~K}$, the viscosity of the basaltic melt decreases from $500 \mathrm{~Pa} \cdot \mathrm{s}$ to about $80 \mathrm{~Pa} \cdot \mathrm{s}$ (Giordano et al., 2008). The relationship between temperature and rate of EC decrease suggests that the reduction in viscosity of the melt phase increases its mobility favouring a faster redistribution of melt during deformation. The increase of conductivity observed once the stress was removed (Fig. 5) was most likely related to interfacial energies, which tends to redistribute the melt into an equilibrium configuration (Parsons et al., 2008; Laporte and Provost, 2000), inducing a slight increase of melt connectivity in the direction of EC measurement.

Microstructural observations suggest, additionally, that the loss of melt connectivity along the radius was associated with the generation of melt-enriched regions approximately parallel to the shear direction (Fig. 6B). This melt-segregation features possibly represents the embryonic stage of generation of melt-bands previously described for partially molten samples deformed in simple shear but at higher strain, with respect to our experiments $(\gamma>1$; Holtzman et al., 2003; Holtzman and Kohlstedt, 2007; Kohlstedt and Holtzman, 2009). These melt-enriched bands develop first at higher shear stress/strain (on the outer portion of cylindrical specimen deformed in torsion) and with increasing deformation, they propagates toward lower stress/strain regions (the core of the sample; King et al., 2010; Kohlstedt and Holtzman, 2009). The increase of shear stress and strain perpendicular to the shear direction effectively result in a gradient in local dilation and compaction, which force the drainage of melt from direction parallel to the gradient to feed melt-enriched bands approximately parallel to the direction of shear. The generation of such bands would increase the melt connectivity and enhance 
significantly the EC in the direction of shear. Consequently, simple shear deformation in presence of a shear stress gradient oriented perpendicular to the shear direction, can generate electrical anisotropy with higher EC in the direction of shear and lower EC in the direction of the stress gradient. More specifically, EC in the shear direction will tend to values corresponding to in-parallel conduction (Hashin and Shtrikman upper bound; (Hashin and Shtrikman, 1962), while in the perpendicular direction EC corresponds to that of an in-series configuration of olivine and melt bearing olivine (Hashin and Shtrikman lower bound; Fig. 7; (Hashin and Shtrikman, 1962). Experimental and theoretical studies on partially molten systems showed that melt redistribution is controlled by pressure gradients (Stevenson, 1989; Jin et al., 1994; Ricard et al., 2001), interfacial energy (Parsons et al., 2008; Hier-Majumder et al., 2006) and, as this experimental work and a recent theoretical study demonstrate (Takei and Holtzman, 2009), by shear stress gradients (see also Hier-Majumder et al., 2004). We performed calculations adapting the model proposed by Takei and Holtzman (2009) to the shear stress gradient present in our torsional experiments to substantiate the possibility of EC variation being associated to melt migration.

\subsection{Numerical simulation of melt-migration velocity}

The same nondimensionalization scheme proposed by Takei and Holtzman (2009) was used for the calculations. The model (Equations 18-23; Takei and Holtzman, 2009) was applied to a system undergoing simple shear deformation in presence of a positive stress gradient from the core to the outer portions of the sample (identical to the stress conditions in our experiments for a material with a stress exponent of 3 (Paterson and 
Olgaard, 2000). This resulted in a different boundary condition for the stress distribution with respect to equation 23 given by Takei and Holtzman (2009), which leads to a solid nondimensional velocity $\left(V_{r}^{S}\right)$ field in the gradient direction given by:

$\frac{b^{2}}{\delta_{c}^{2}} V_{r}^{S}-\frac{\partial}{\partial r}\left(\frac{\partial V_{r}^{S}}{\partial r}+\frac{V_{r}^{S}}{r}\right)=-\frac{2 b^{2} \eta_{0} \gamma k_{\phi}}{\delta_{c}^{2} \eta_{L} \tau_{\max }} \frac{\partial \tau}{\partial r}$

where $b$ is the radius of the cylindrical system in meters, $d_{c}$ is the compaction length (Fig. 8), $r$ is the nondimensional radius, $h_{0}$ is the isotropic viscosity of the system, $g$ is the nondimensional coupling factor (given by Equation 11 of Takei and Holtzman, 2009), $k_{f}$ is the permeability (calculated following the formulation proposed by (Holtzman et al., 2003) $t$ is the shear stress, $h_{L}$ is the liquid viscosity (80 Pa·s; Giordano et al., 2008), $t_{\max }$ is the maximum shear stress value applied on the outer portions of the specimen. For the calculations, the same shear stress distribution given by torsional deformation in Paterson apparatus (Paterson and Olgaard, 2000) was used:

$\tau(r)=\left(\frac{2 r}{b}\right)^{\frac{1}{3}} \tau_{\max }$

Due to the presence of a central nickel electrode in our samples, we considered only the stress gradient between the electrode and the outer part of the specimens. Equation 5 was solved by finite difference method. The mass conservation equation allows computing the nondimensional liquid velocity $\left(V_{r}^{L}\right)$ field:

$V_{r}^{L}=\frac{\phi-1}{\phi} V_{r}^{S}$

where $f$ is the porosity (melt volume fraction) of the system. Using input values appropriate for experiment 8B a maximum velocity of about $200 \mu \mathrm{m} / \mathrm{hr}$ was obtained for sample 8B (melt volume fraction of 0.116 ). This velocity results in a total maximum 
displacement of about $1.2 \mathrm{~mm}$ in 6 hours, which is comparable to that observed in the experiment PP110 after 6 hours deformation (Fig. 8). In summary the calculations predict that the melt migrates to the high shear-stress portions of the sample (Fig. 1; Paterson and Olgaard, 2000) within the same time-scale of the experiments (Fig. 8), confirming the control of shear stress gradients on the observed melt redistribution (Fig. 6).

Needless to say, the segregation of melt observed in our experiments occurred at higher stresses and strain rates in comparison to deformation in the Earth’s mantle. Segregation of melt is controlled by stress gradients and surface tension. Parson et al. (2008) and Kohlstedt and Holtzman (2009) showed that both for experiments and conditions relevant to the asthenosphere, differential stresses dominate over surface tension, which tend to equally redistribute the melt-phase in a partially molten rock. They also demonstrate that the rate of melt segregation is higher than the rate of melt redistribution by surface tension. An additional factor that could be important in the mantle is the interplay between stress and buoyancy driven segregation. Numerical models seem to demonstrate that stress induced segregation will dominate at mid-ocean ridges (Kohlstedt and Holtzman, 2009) over short length scales whereas buoyancy driven segregation will dominate over longer length scales (Rutter and Mecklenburgh, 2006). However, the analyses of the relative effects of stress and buoyancy for the melt segregation mechanisms proposed in our work is beyond the scope of this paper. Future studies focusing on this aspect may be of extreme importance.

\section{Implications for anisotropy at the Lithosphere-Asthenosphere boundary}

The LAB underneath mid-oceanic plates is characterized by a significant increase of EC and a decrease in seismic wave propagation velocity at depths between 70 and $150 \mathrm{~km}$ 
(Forsyth et al., 1998; Evans et al., 2005; Baba et al., 2006; Kawakatsu et al., 2009; Rychert and Shearer, 2009). A horizontal layering of melt-rich and melt-depleted mantle in the LAB in the direction of spreading has been proposed and could account for these geophysical observations (Kawakatsu et al., 2009). This layering could be generated by simple shear resulting from the rheological decoupling between the lithosphere and the less viscous asthenosphere (Holtzman et al., 2003; Holtzman and Kohlstedt, 2007; Takei and Holtzman, 2009). However, such shear geometry would not generate the observed anisotropy in EC between the ridge-parallel and spreading directions (Evans et al., 2005; Baba et al., 2006; Evans, 2008), since it would produce two-dimensional melt planes subparallel to the LAB (Holtzman et al., 2003; Holtzman and Kohlstedt, 2007) and the EC would be the same in both the ridge parallel and spreading directions. Anisotropy of electrical conductivity can be generated by high degree of melt connectivity in the spreading direction coupled with low connectivity in the ridge parallel direction (Figs. 9, 10). The low connectivity in the ridge parallel direction could operate by structures either at the grain scale (few millimetres) or at the scale of several tens of kilometres given the lateral resolution of magneto-telluric surveys at depth of $\sim 100-150 \mathrm{~km}$.

Several mechanisms such as small-scale sub-lithospheric convection and viscous fingering of the asthenosphere have been proposed for the generation of melt-enriched channels in the spreading direction (e.g. Jha et al., 1997; Weeraratne et al., 2007; Ballmer et al., 2009). Regions of high melt fraction coexisting with melt-poorer regions aligned along the spreading direction would necessarily result in differences in viscosity in the same direction. Different viscosities imply partitioning of strain at the LAB and gradients in stress/strain rate along the ridge direction. Experiments and calculations performed in 
this study show that stress/strain gradients and gradients in melt fraction are intimately related, being capable of positive feedbacks that can result in the rapid drainage of melt. More precisely, our experiments show that these gradients perpendicular to the shear direction (i.e. ridge parallel direction) tend to reduce the degree of melt connectivity in the direction of the stress gradient, which could be responsible for the generation of channel-like melt-enriched structures in the direction of MOR spreading. As a consequence, sub-lithospheric convection and viscous fingering could induce inhomogeneity in melt distribution, resulting in viscosity variation of the LAB, which combined with stress/strain driven melt redistribution could culminate in the generation of melt-enriched channels elongated in the spreading direction, a structure that could account for the electrical anisotropy at the LAB (Figs. 9, 10).

The development of melt-enriched channels elongated in the spreading direction can therefore go along with, and may most likely be faster than, the spreading of the lithosphere. At increasing distance from the MOR, the decrease of decoupling between lithosphere and asthenosphere should reduce the intensity of melt redistribution and decrease the degree of electrical anisotropy away from the MOR axis. Electrical conductivity at the EPR in the ridge-parallel direction seems in fact to increase (i.e. reducing the degree of anisotropy) with increasing distance from the ridge (see Figure 1 of Evans et al., 2005; and Figure 3 of Baba et al., 2006).

The proposed organization of the melt not only can account for the anisotropy measured during the MELT experiment (Evans et al., 2005; Baba et al., 2006; Figs. 9A, 10, Table 2 online material) but could also give an explanation to a number of independent observations. The analysis of a global dataset of spreading velocity (Muller et al., 2008) 
reveals that the spreading rates in MOR sectors contained between transform faults are not constant. At the EPR, velocities vary between between 88 and $90 \mathrm{~mm} / \mathrm{y}$ with a wavelength of the order of tens of kilometres (Muller et al., 2008; Fig. 9C), which might reflect gradients in melt fraction (i.e. rheology gradients) at the LAB (Turcotte and Schubert, 2002). Additionally seamounts tend to be aligned in direction perpendicular to the MOR (Fig. 9C), and ${ }^{30} \mathrm{Th}^{-238} \mathrm{U}$ disequilibrium show that magma erupted as far as 40 km away from the ridge axis have been transported considerably faster (190-210 mm/yr) than the average spreading rates (Zou et al., 2002). The presence of melt-rich channels in the spreading direction could account for the distribution of seamounts and would allow the fast transfer of magma toward off-axis locations. Finally, melt-rich channels at the LAB would imply the lateral extraction at depth of a melt fraction that does not reach the ridge axis. If, as indicated by geophysical surveys, such an extraction occurs at 100-150 $\mathrm{km}$ depth underneath the ridge where very low degree of mantle melting occurs (Baba et al., 2006; Gaillard et al., 2008), this extraction process must deplete the source of MOR volcanism in incompatible and volatile elements (Gaillard et al., 2008; see also partitioning data in Hammouda et al., 2009). Melts produced at $150 \mathrm{~km}$ underneath the ridge are carbonatites whereas melts produced at $100 \mathrm{~km}$ are believed to be carbonated basalts, i.e. sort of hybrid between carbonatites and basalts (Hirschmann, 2010). It is therefore possible that the lateral removal of such chemically enriched liquids from the deepest melting zones is accompanied by emissions of depleted basalts at the ridge, whereas portions where such removal does not occur are associated to a relatively enriched MOR volcanism. The sporadic occurrence of E-MORB (exposed both off-axis and on axis) and generally embedded by N-MORB at the EPR (Niu et al., 2002) and 
elsewhere (Donnelly et al, 2004) might be related to such lateral extraction in depth. EMORB, notably richer in Nb relative to N-MORB (Niu et al., 2002), must accordingly derive from a $\mathrm{CO}_{2}$ richer mantle source (Le Roux et al., 2006). Such mantle source, rich in carbonatites or carbonated basalts, is therefore electrically conductive. Such geometry of MOR plumbing systems provides a rationale to interpret electrical anisotropy at the $\mathrm{LAB}$ and could exert a control on the chemistry and distribution of magmas that erupt at constructive plate margins.

\section{Acknowledgements}

The authors acknowledge the financial support received by an INSU grant and the Electrovolc project, supported by the French national agency for research (ANR): contract JC05-42707 allocated to F.G. The scientific discussions with Remi Champallier and the technical support of Philippe Teulat are greatly appreciated. We would like to thank Elisabetta Mariani for constructive comments, which help clarify this paper. We acknowledge three anonymous reviewers for their thorough comments on an earlier version that significantly improved this paper.

\section{References}

Abramoff, M.D., Magelhaes, P.J., Ram, S.J. (2004). Image Processing with Image. J. Biophotonics International 11 (7) 36-42.

Baba, K., Chave, A.D., Evans, R.L., Hirth, G., Mackie, R.L., (2006). Mantle dynamics beneath the East Pacific Rise at 17 degrees S: Insights from the Mantle Electromagnetic 
and Tomography (MELT) experiment. Journal of Geophysical Research-Solid Earth 111, doi: 10.1029/2004jb003598.

Ballmer, M.D., van Hunen, J., Ito, G., Bianco, T.A., Tackley, P.J., (2009). Intraplate volcanism with complex age-distance patterns: A case for small-scale sublithospheric convection. Geochemistry Geophysics Geosystems 10, Q06015, doi:10.1029/2009GC002386.

Constable, S., Duba, A., (1990). Electrical-Conductivity of Olivine, a Dunite, and the Mantle. Journal of Geophysical Research-Solid Earth and Planets 95, 6967-6978.

Donnelly, K.E., Goldstein, S.L., Langmuir, C.H., Spiegelman, M. (2004). Origin of enriched ocean ridge basalts and implications for mantle dynamics. Earth and Planetary Science Letters 226, 347-366.

Evans, R.L., (2008). Geochemistry Carbon in Charge. Science 322, 1338-1340.

Evans, R.L., Hirth, G., Baba, K., Forsyth, D., Chave, A., Mackie, R., (2005). Geophysical evidence from the MELT area for compositional controls on oceanic plates. Nature 437, 249-252.

Forsyth, D.W., Scheirer, D.S., Webb, S.C., Dorman, L.M., Orcutt, J.A., Harding, A.J., Blackman, D.K., Morgan, J.P., Detrick, R.S., Shen, Y., Wolfe, C.J., Canales, J.P., Toomey, D.R., Sheehan, A.F., Solomon, S.C., Wilcock, W.S.D., Team, M.S., (1998). Imaging the deep seismic structure beneath a mid-ocean ridge: The MELT experiment. Science 280, 1215-1218.

Frost, H., Ashby, M., Deformation mechanism maps, Pergamon Press, New York, 1982. Gaillard, F., (2004). Laboratory measurements of electrical conductivity of hydrous and dry silicic melts under pressure. Earth and Planetary Science Letters 218, 215-228. 
Gaillard, F., Marziano, G.I., (2005). Electrical conductivity of magma in the course of crystallization controlled by their residual liquid composition. Journal of Geophysical Research-Solid Earth 110, B06204, doi:10.1029/2004JB003282.

Gaillard, F., Malki, M., Iacono-Marziano, G., Pichavant, M., Scaillet, B., (2008). Carbonatite Melts and Electrical Conductivity in the Asthenosphere. Science 322, 13631365.

Giordano, D., Russell, J.K., Dingwell, D.B., (2008). Viscosity of magmatic liquids: A model. Earth and Planetary Science Letters 271, 123-134.

Hammouda T., Moine B.N., Devidal J.L. and Vincent C., (2008) Trace element partitioning during partial melting of carbonated eclogites, Physics of the Earth and Planetary Interior 174, 60-69.

Hashin, Z., Shtrikman, S., (1962). A Variational Approach to Theory of Effective Magnetic Permeability of Multiphase Materials. Journal of Applied Physics 33, 31253155.

Heege, J.H., Renner, J., (2007). In situ impedance spectroscopy on pyrophyllite and $\mathrm{CaCO} 3$ at high pressure and temperature: phase transformations and kinetics of atomistic transport. Physics and Chemistry of Minerals 34, 445-465.

Hier-Majumder, S., Leo P.H., and Kohlstedt D.L. (2004). On grain boundary wetting during deformation, Acta Material 52, 3425-3433

Hier-Majumder, S., Ricard, Y., Bercovici, D. (2006). Role of grain boundaries in magma migration and storage. Earth and Planetary Science Letters 248, 735-749

Hirschmann, M.M., (2010). Partial melt in the oceanic low velocity zone. Physics of the Earth and Planetary Interior 179, 60-71. 
Hirth, G., Kohlstedt, D.L., (1995). Experimental Constraints on the Dynamics of the Partially Molten Upper-Mantle .2. Deformation in the Dislocation Creep Regime. Journal of Geophysical Research-Solid Earth 100, 15441-15449.

Hirth, G. \& Kohlstedt, D. L. 2003. Rheology of the upper mantle and mantle wedge: a view from the experimentalist. In: Inside the subduction factory (edited by Eiler, J.). Geophysical Monograph 138. American Geophysical Union, Washington D. C., 83-105.

Holness, M. B. (2006) Melt-solid dihedral angles of common minerals in natural rocks. Journal of Petrology, 47 . 791-800.

Holtzman, B.K., Kohlstedt, D.L., (2007). Stress-driven melt segregation and strain partitioning in partially molten rocks: Effects of stress and strain. Journal of Petrology 48, 2379-2406.

Holtzman, B. K., Groebner, N. J., Zimmerman, M. E., Ginsberg, S. B. \& Kohlstedt, D. L. 2003. Stress-driven melt segregation in partially molten rocks. Geochemistry, Geophysics, Geosystems 4(5), doi:10.1029/2001GC000258.

Holtzman, B.K., Kohlstedt, D.L., Zimmerman, M.E., Heidelbach, F., Hiraga, T., Hustoft, J., (2003). Melt segregation and strain partitioning: Implications for seismic anisotropy and mantle flow. Science 301, 1227-1230.

Jha, K., Parmentier, E.M., Sparks, D.W., (1997). Buoyant mantle upwelling and crustal production at oceanic spreading centers: On-axis segmentation and off-axis melting. Journal of Geophysical Research-Solid Earth 102, 11979-11989.

Jin, Z.M., Green, H.W., Zhou, Y., (1994). Melt Topology in Partially Molten Mantle Peridotite during Ductile Deformation. Nature 372, 164-167. 
Kawakatsu, H., Kumar, P., Takei, Y., Shinohara, M., Kanazawa, T., Araki, E., Suyehiro, K., (2009). Seismic Evidence for Sharp Lithosphere-Asthenosphere Boundaries of Oceanic Plates. Science 324, 499-502.

King, D.S.H., Zimmerman, M.E., Kohlstedt D.L, (2010). Stress-driven melt segregation in partially molten olivine-rich rocks deformed in torsion. Journal of Petrology 51 (1-2), 21-42.

Kohlstedt, D. L. 2002. Partial melting and deformation. In: Plastic deformation in minerals and rocks (edited by Karato, S. I. \& Wenk, H. R.). Reviews in mineralogy and geochemistry 51. Mineralogical Society of America, Washington DC, 121-135.

Kohlstedt, D.L., Holtzman, B.K., (2009). Shearing Melt Out of the Earth: An Experimentalist's Perspective on the Influence of Deformation on Melt Extraction. Annual Review of Earth and Planetary Sciences 37, 561-593.

Lange, R.A., (1996). Temperature independent thermal expansivities of sodium aluminosilicate melts between 713 and 1835 K. Geochimica Et Cosmochimica Acta 60, 4989-4996.

Lange, R.A., (1997). A revised model for the density and thermal expansivity of K2ONa2O-CaO-MgO-Al2O3-SiO2 liquids from 700 to $1900 \mathrm{~K}$ : extension to crustal magmatic temperatures. Contributions to Mineralogy and Petrology 130, 1-11.

Lange, R.A., Carmichael, I.S.E., (1987). Densities of Na2O-K2O-CaO-MgO-FeOFe2O3-Al2O3-TiO2-SiO2 Liquids - New Measurements and Derived Partial Molar Properties. Geochimica Et Cosmochimica Acta 51, 2931-2946. 
Laporte, D., Provost, A., (2000). Equilibrium geometry of a fluid phase in a polycrystalline aggregate with anisotropic surface energies: Dry grain boundaries. Journal of Geophysical Research-Solid Earth 105, 25937-25953.

le Roux, P.J., Shirey, S.B., Hauri E.H., Perfit, M.R., Bender, J.F. (2006). The effects of variable sources, processes and contaminants on the composition of northern EPR MORB (8-10 degrees $\mathrm{N}$ and 12-14 degrees $\mathrm{N})$ : Evidence from volatiles (H2O, CO2, S) and halogens (F, Cl). Earth and Planetary Science Letters 251, 209-231.

Maumus, J., Bagdassarov, N., Schmeling, H., (2005). Electrical conductivity and partial melting of mafic rocks under pressure. Geochimica Et Cosmochimica Acta 69, 47034718.

Mecklenburgh, J., Heidelbach, F., Gaillard, F., Electrical conductivity of marbles during torsion Annual report of the Bayerisches Geoinstitut, 2003.

Muller, R.D., Sdrolias, M., Gaina, C., Roest, W.R., (2008). Age, spreading rates, and spreading asymmetry of the world's ocean crust. Geochemistry Geophysics Geosystems 9, doi: 10.1029/2007gc001743.

Niu, Y.L., Regelous, M., Wendt, I.J., Batiza, R., O'Hara, M.J. (2002). Geochemistry of near-EPR seamounts: importance of source vs. process and the origin of enriched mantle component. Earth and Planetary Science Letters 199, 327-345.

Orazem, M. E. \& Tribollet, B. 2008. Electrochemical impedance spectroscopy. John Wiley \& Sons.

Parsons, R.A., Nimmo, F., Hustoft, J.W., Holtzman, B.K., Kohlstedt, D.L., (2008). An experimental and numerical study of surface tension-driven melt flow. Earth and Planetary Science Letters 267, 548-557. 
Paterson, M.S., Olgaard, D.L., (2000). Rock deformation tests to large shear strains in torsion. Journal of Structural Geology 22, 1341-1358.

Pichavant, M., Macdonald, R., (2007). Crystallization of primitive basaltic magmas at crustal pressures and genesis of the calc-alkaline igneous suite: experimental evidence from St Vincent, Lesser Antilles arc. Contributions to Mineralogy and Petrology 154, 535-558.

Pommier, A., Gaillard, F., Pichavant, M., Scaillet, B., (2008). Laboratory measurements of electrical conductivities of hydrous and dry Mount Vesuvius melts under pressure. Journal of Geophysical Research-Solid Earth 113, doi: 10.1029/2007jb005269.

Pommier, A., Gaillard, F., Malki, M., Pichavant, M., (2010). Methodological reevaluation of the electrical conductivity of silicate melts. American Mineralogist 95, 284291.

Ricard, Y., Bercovici, D., Schubert, G., (2001). A two-phase model for compaction and damage 2. Applications to compaction, deformation, and the role of interfacial surface tension. Journal of Geophysical Research-Solid Earth 106, 8907-8924.

Roberts, J.J., Tyburczy, J.A., (1994). Frequency-Dependent Electrical-Properties of Minerals and Partial-Melts. Surveys in Geophysics 15, 239-262.

Roberts, J.J., Tyburczy, J.A., (1999). Partial-melt electrical conductivity: Influence of melt composition. Journal of Geophysical Research-Solid Earth 104, 7055-7065.

Rutter, E. H. \& Mecklenburgh, J. 2006. The extraction of crustal melts from their protolith and the flow behavior of partially molten crustal rocks. In: Evolution and differentiation of the continental crust (edited by Brown, M. \& Rushmer, T.). Cambridge University Press, Cambridge, 384-429. 
Rychert, C.A., Shearer, P.M., (2009). A Global View of the Lithosphere-Asthenosphere Boundary. Science 324, 495-498.

Sato, H., Ida, Y., (1984). Low-Frequency Electrical-Impedance of Partially Molten Gabbro - the Effect of Melt Geometry on Electrical-Properties. Tectonophysics 107, 105134.

Stevenson, D.J., (1989). Spontaneous Small-Scale Melt Segregation in Partial Melts Undergoing Deformation. Geophysical Research Letters 16, 1067-1070.

Takei, Y., Holtzman, B.K., (2009). Viscous constitutive relations of solid-liquid composites in terms of grain boundary contiguity: 3. Causes and consequences of viscous anisotropy. Journal of Geophysical Research-Solid Earth 114, doi: 10.1029/2008jb005852.

ten Grotenhuis, S.M., Drury, M.R., Spiers, C.J., Peach, C.J., (2005). Melt distribution in olivine rocks based on electrical conductivity measurements. Journal of Geophysical Research-Solid Earth 110, doi: 10.1029/2004jb003462.

Turcotte, D.L., Schubert, G., Geodynamics, Cambridge University Press, 2002.

Watanabe, T., Kurita, K., (1993). The Relationship between Electrical-Conductivity and Melt Fraction in a Partially Molten Simple System - Archie Law Behavior. Physics of the Earth and Planetary Interiors 78, 9-17.

Weeraratne, D.S., Forsyth, D.W., Yang, Y.J., Webb, S.C., (2007). Rayleigh wave tomography beneath intraplate volcanic ridges in the South Pacific. Journal of Geophysical Research-Solid Earth 112, doi: 10.1029/2006JB004403. 
Wendlandt, R.F., Eggler, D.H., (1980). The Origins of Potassic Magmas .2. Stability of Phlogopite in Natural Spinel Lherzolite and in the System Kalsio4-Mgo-Sio2-H2o-Co2 at High-Pressures and High-Temperatures. American Journal of Science 280, 421-458.

Yoshino, T., Matsuzaki, T., Yamashita, S., Katsura, T., (2006). Hydrous olivine unable to account for conductivity anomaly at the top of the asthenosphere. Nature 443, 973-976.

Zimmerman, M. E., Zhang, S. \& Kohlstedt, D. L. 1999. Melt distribution in mantle rocks deformed in shear. Geophysical Research Letters 26(10), 1505-1508.

Zou, H.B., Zindler, A., Niu, Y.L., (2002). Constraints on melt movement beneath the East Pacific Rise from Th-230-U-238 disequilibrium. Science 295, 107-110. 
Figure captions 
Shielded N-type Thermocouple

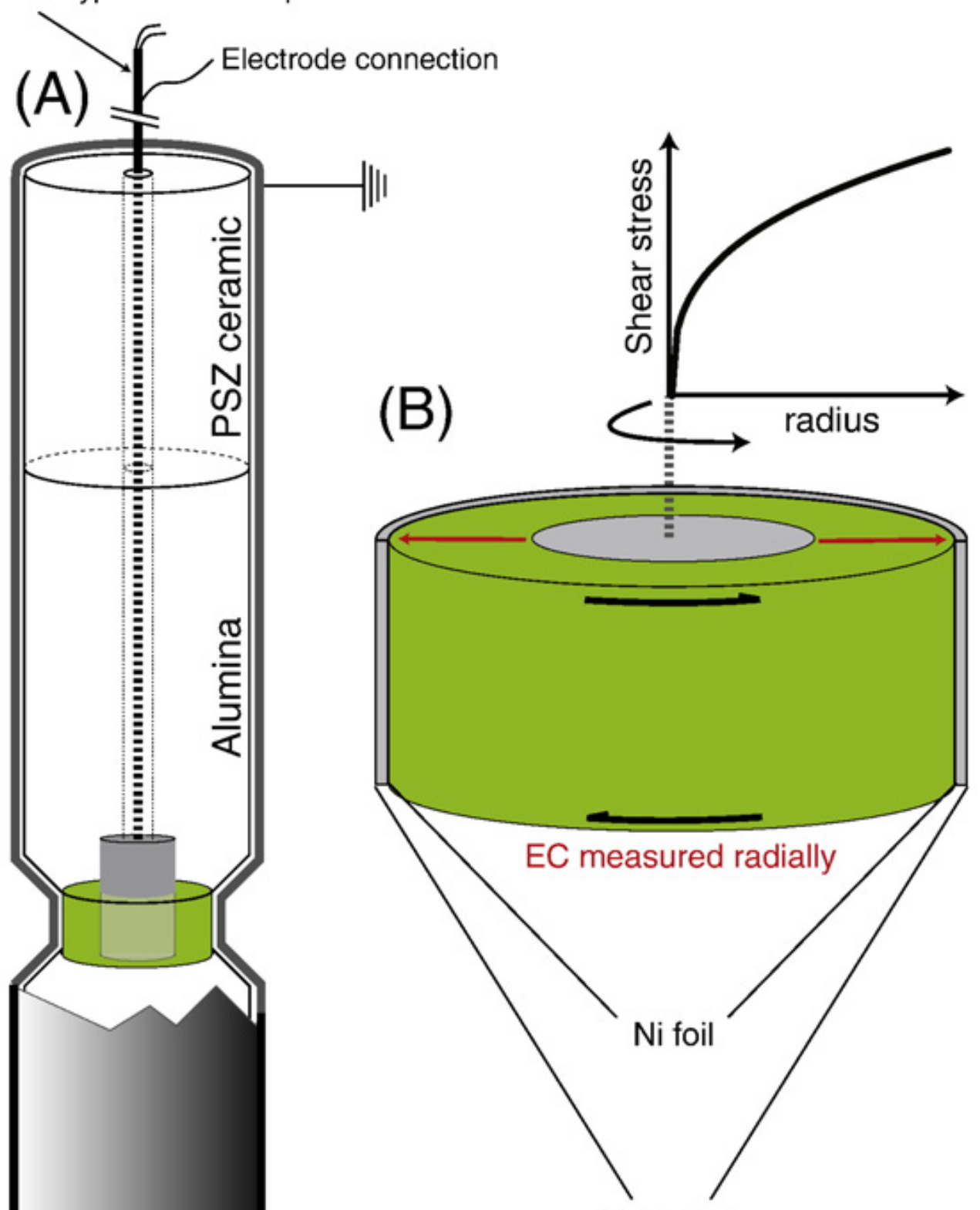

Fe-jacket 
Figure 1: (A) Sketch of the experimental assembly used to perform electrical conductivity measurement in static conditions and during deformation in simple shear. During the measurement the assembly is isostatically pressurized using Argon gas. (B) Enlarged sketch of the sample. The plot on top gives the shear stress distribution for a material with a stress exponent of 3 (as measured in these experiments), according to Paterson and Olgaard (2000). The red arrows give the direction of measurement of EC. The grey central cylinder and the external metallic sheet are the two electrodes hence EC is measured in coaxial geometry. 
(A)

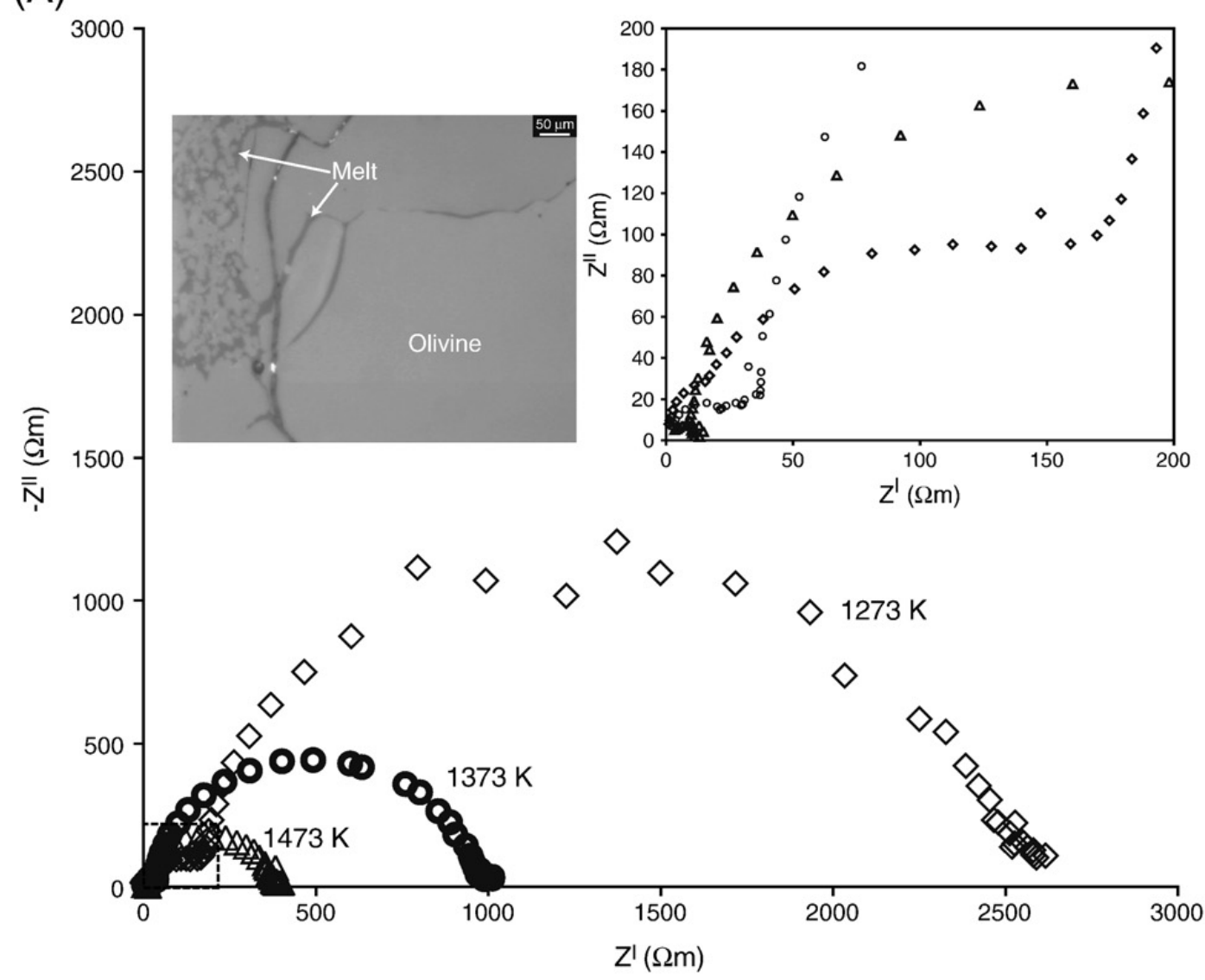

(B)

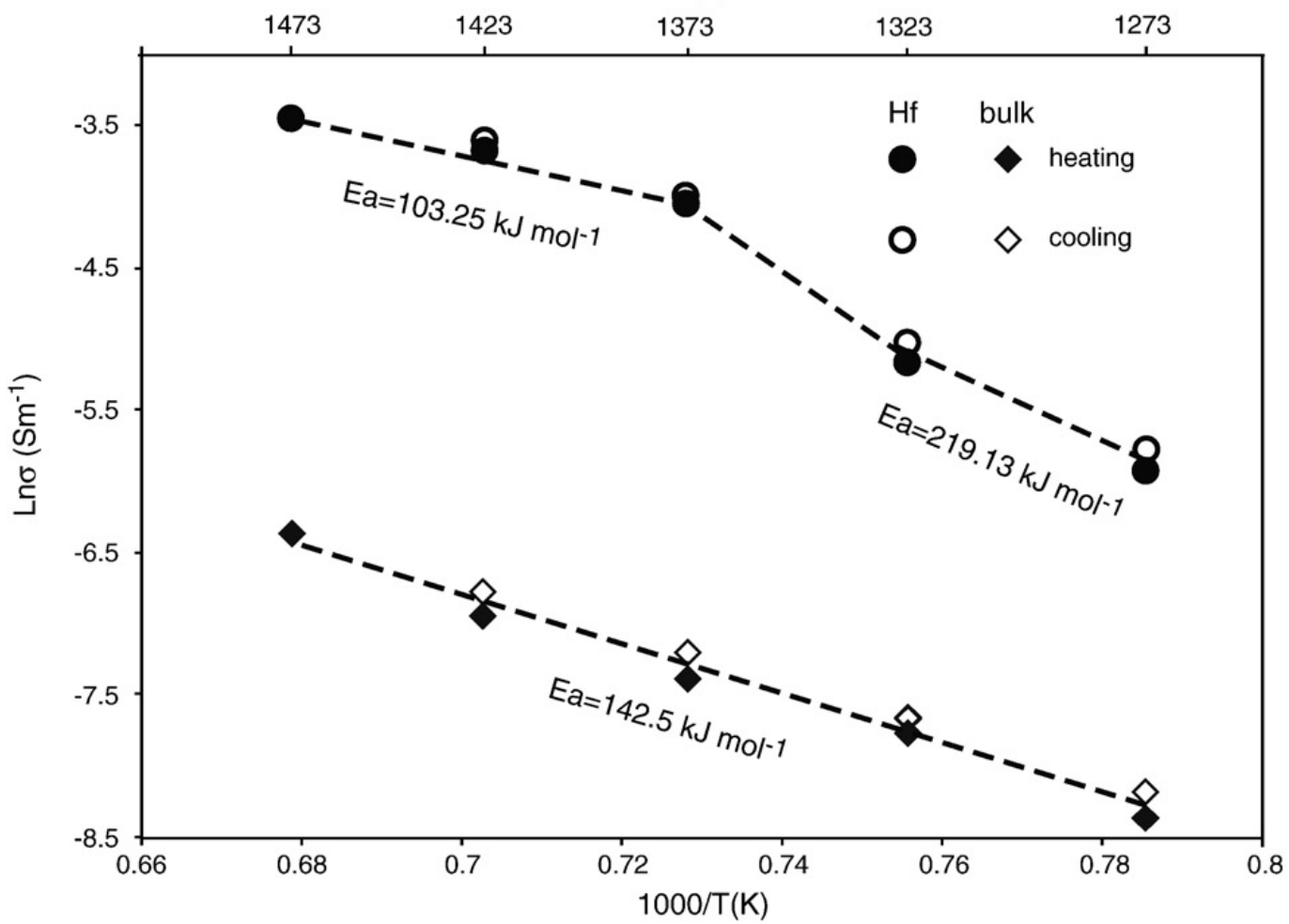


Figure 2: (A) Impedance spectra collected between 1273 and 1473K for Åheim dunite, plotted in the Nyquist plane. On the top left back scattered electrons (BSE) image of the sample recovered after the experiment. In the image are visible the products of reaction of phlogopite, including melt. On the top right, enlargement of the high frequency portions of the spectra. (B) Natural logarithm of the electrical conductivity (s) plotted as function of the inverse of the temperature. The numbers close to the lines represent the values of activation energy $(\mathrm{Ea})$ for the different conduction mechanism (bulk and high frequency (Hf)). 


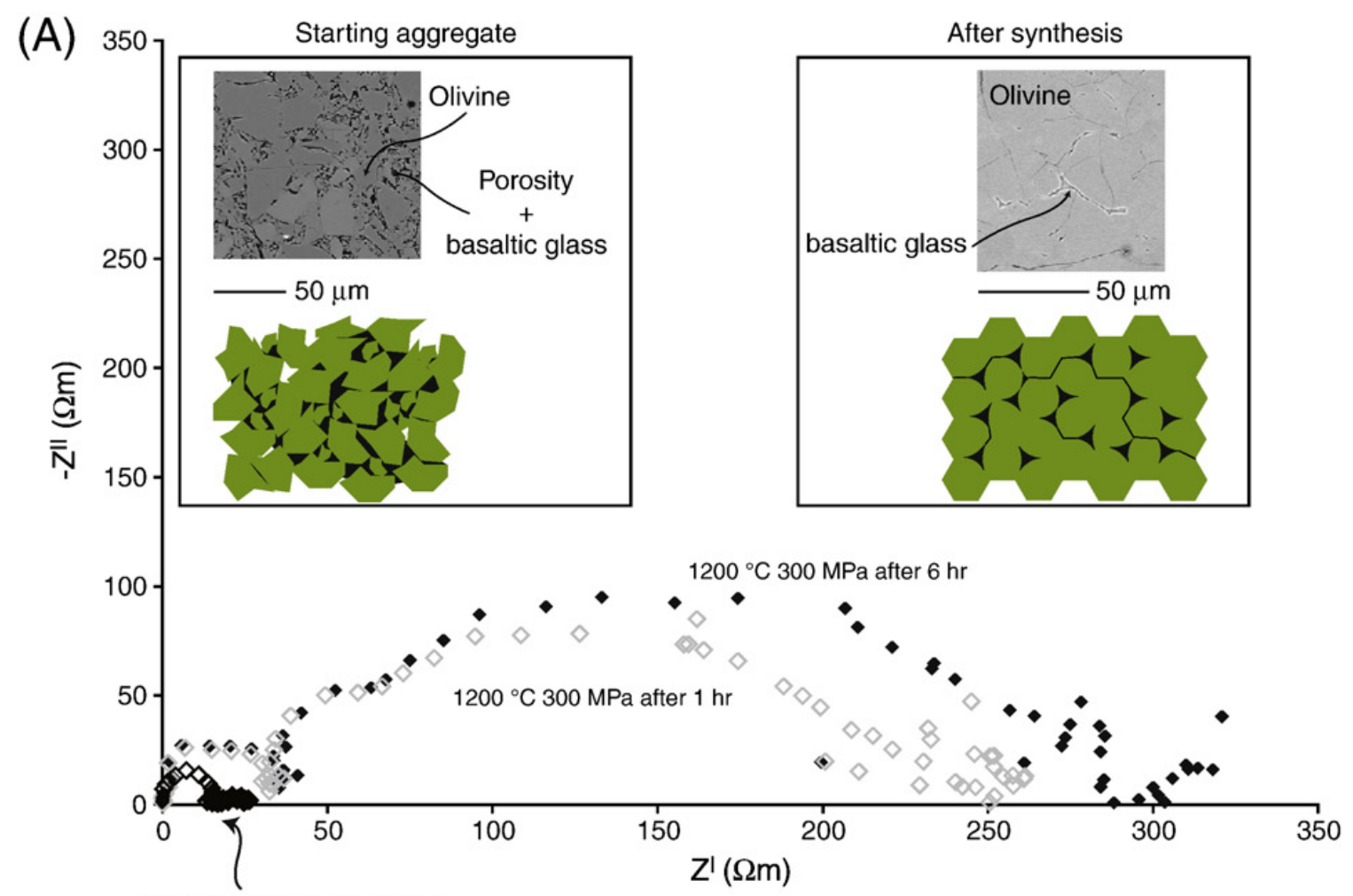
$1473 \mathrm{~K}$ first measurement

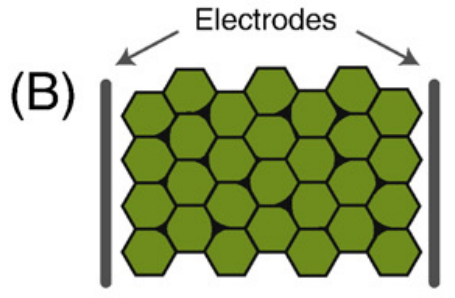

High Frequency Arc=HF

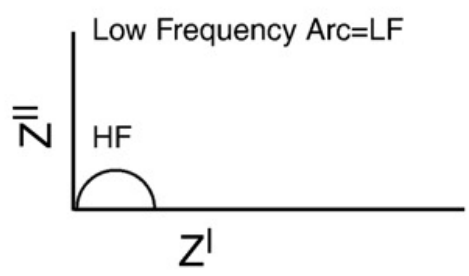

(C)
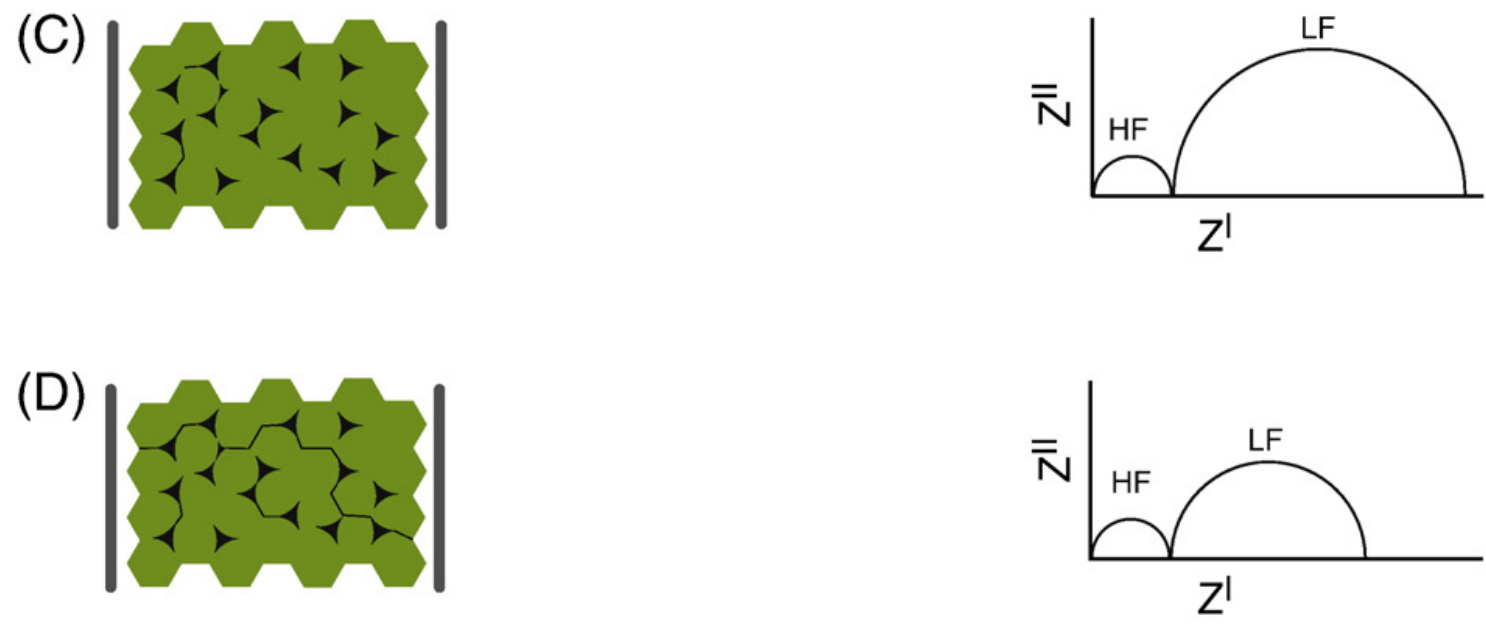
Figure 3: (A) Impedance spectra as function of frequency represented in the Nyquist plane during sintering of a sample containing $8 \mathrm{wt}$.\% basalt. The two boxes contain backscattered electron images collected with an SEM (on top) and a schematic interpretation of the aggregate texture before (left hand side) and after the synthesis (right hand side). During the first hour in pressure and temperature the impedance is in agreement with an olivine-basalt mixture in which the melt is fully connected. After about 1 hour the impedance increases strongly testifying the attainment of an almost equilibrated texture with melt mainly distributed on the olivine triple junctions. (B-D) Schematic representations of the melt (in black) and olivine (in green) distribution and the associated electrical response as function of frequency. 

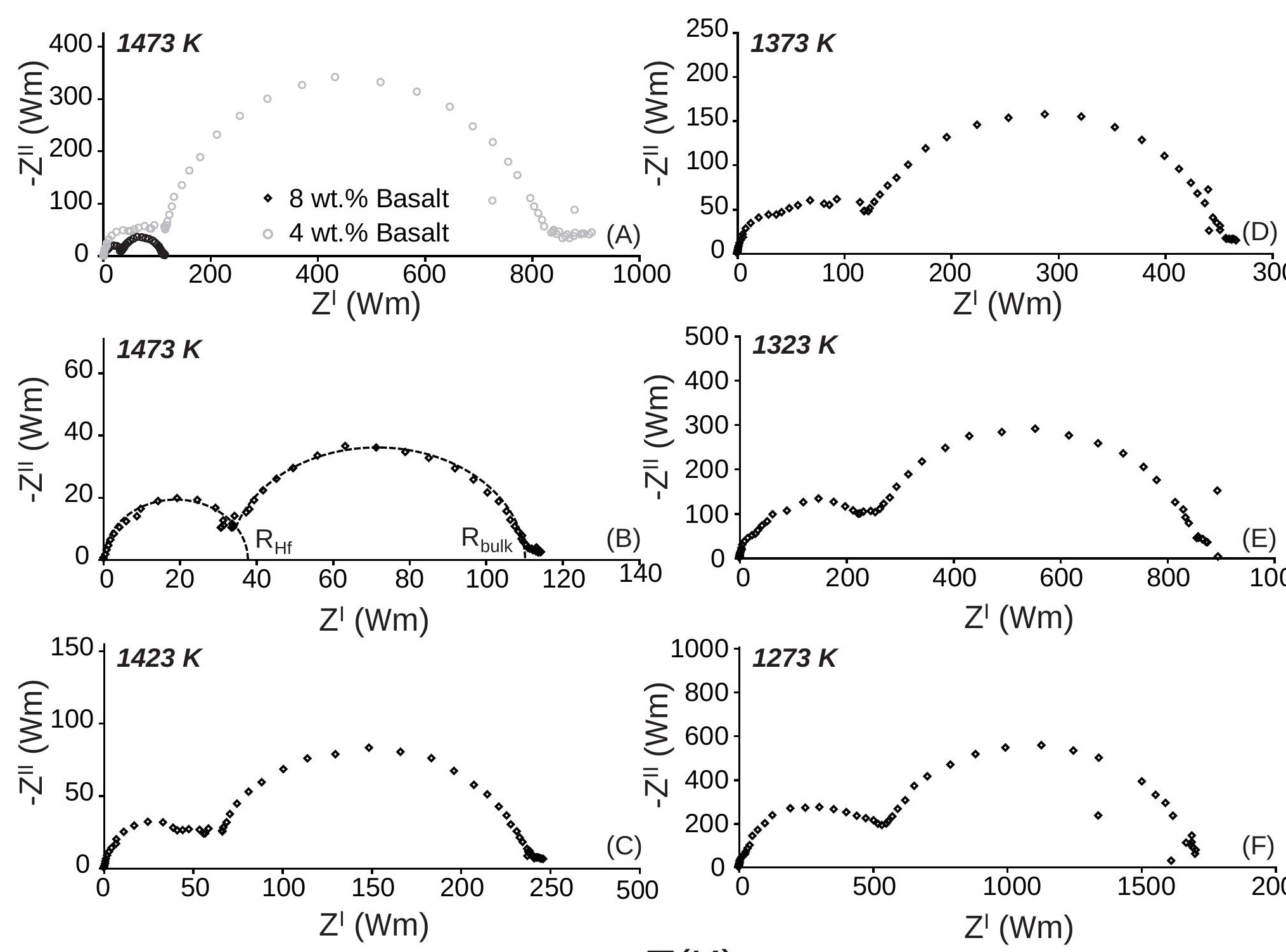

$\mathrm{T}(\mathrm{K})$

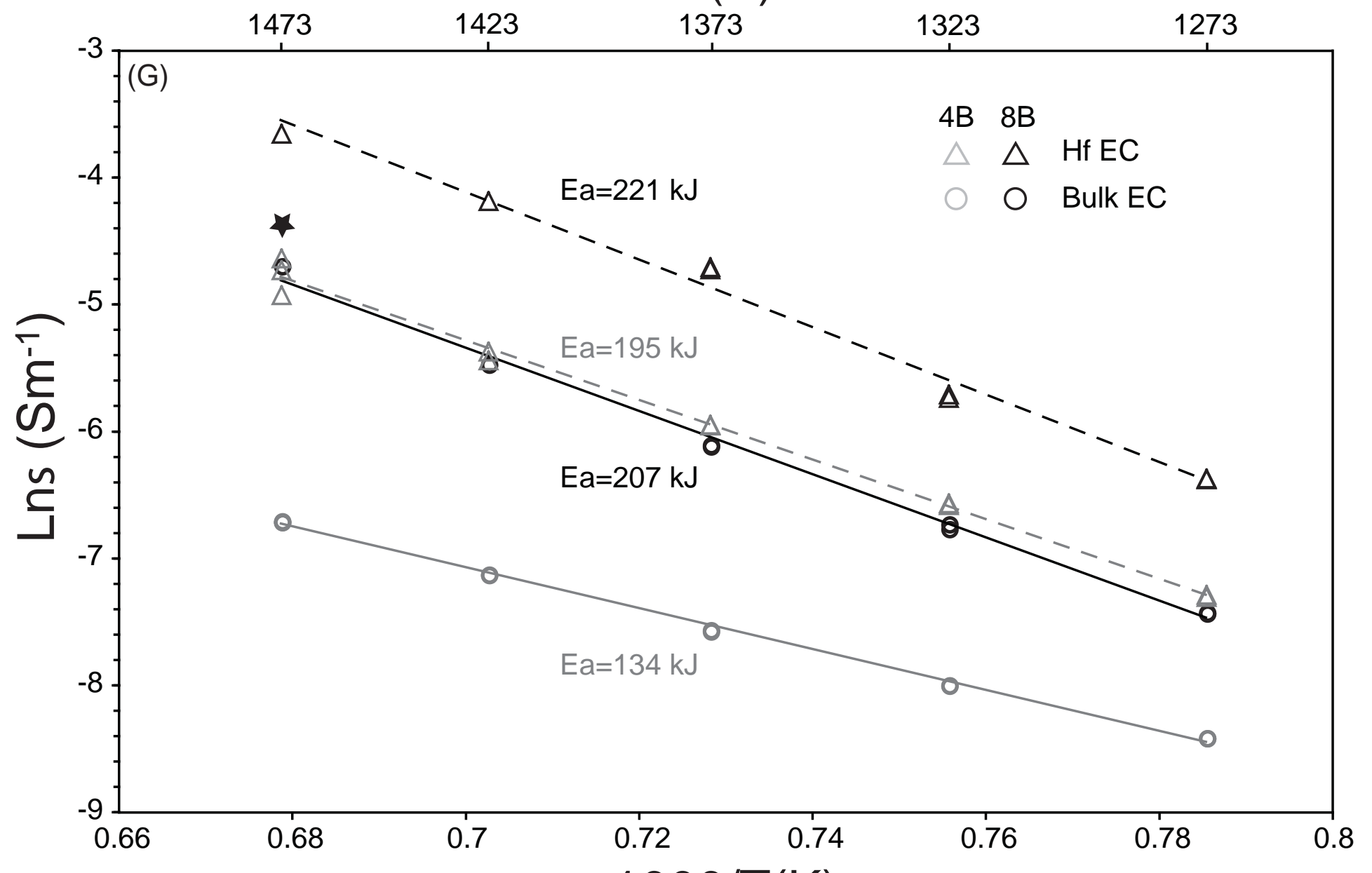


Figure 4: (A-F) Series of impedance spectra collected for a sample containing 8wt.\% basalt between 1473 and 1273 K. In Figure A, spectra for samples containing 4 and 8 wt.\% basalt are compared. The scale for each figure changes because of space limitations. (G) Variation of the natural logarithm of the electrical conductivity (s) against the inverse of temperature for the conductivity associated to the Hf mechanism (triangles) and the bulk conductivity (circles). The lines are the fitting to obtain the activation energy (Ea, number reported close to the lines) for the different conduction mechanisms and the different samples.
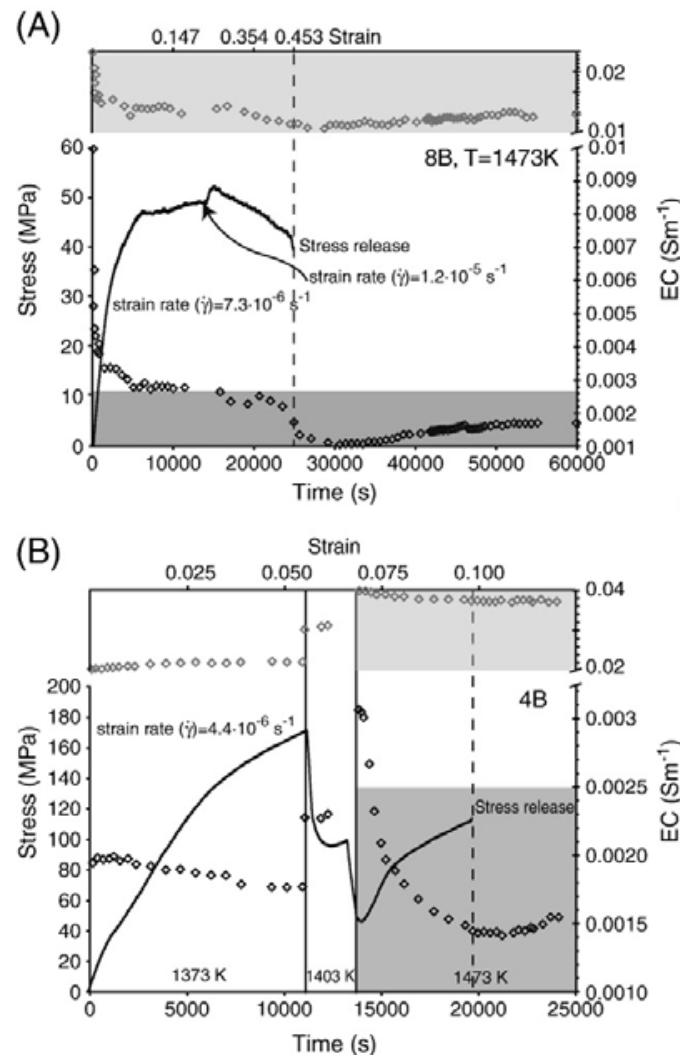

(C)

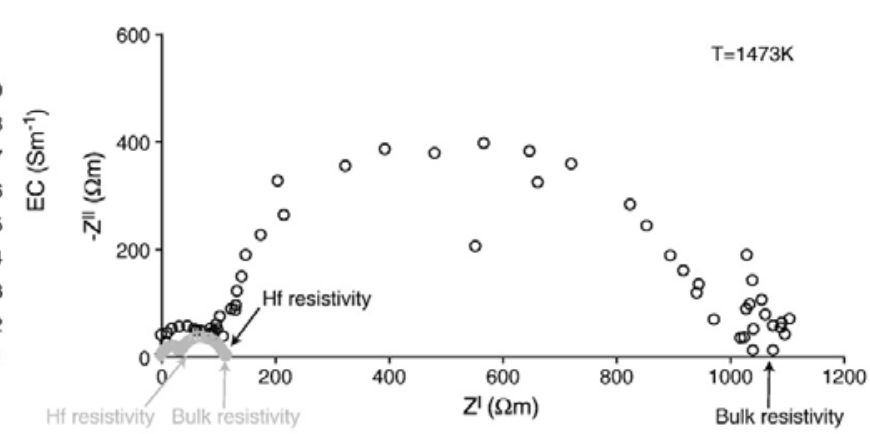

(D)

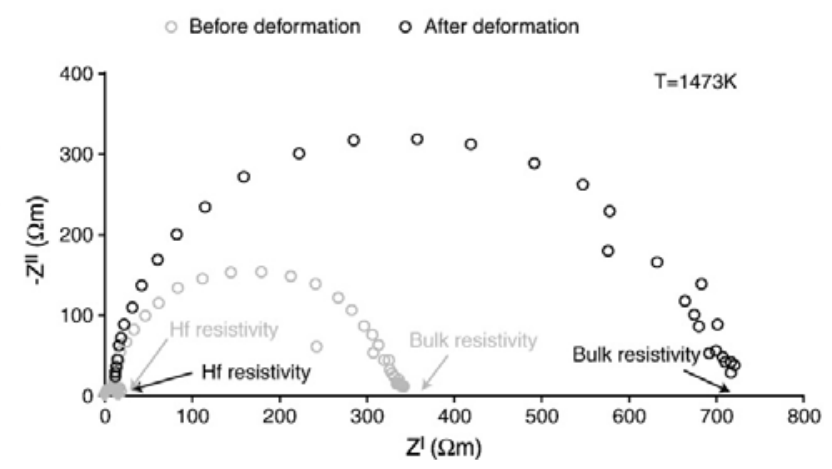

Figure 5: Variation of stress and EC during deformation of sample 8B (A) and 4B (B) with increasing deformation. The black lines give the variation of stress with increasing time and strain, the grey symbols show the EC associated to the HF conduction 
mechanism and the black symbols give the bulk EC. The light grey area covers the previously measured values of high frequency EC for partially molten rocks (Roberts and Tyburczy, 1999), while the green area represent the EC determined for olivine aggregates (Constable and Duba, 1990). Both the areas give the range of EC values measured at 1473 K. (A) In the experiment shown in Figure 5A after a strain rate increase from $7.3 \cdot 10^{-6} \mathrm{~s}^{-1}$ to $1.2 \cdot 10^{-5} \mathrm{~s}^{-1}$ shear weakening was observed. The strong decrease of bulk EC is associated with an only minor decrease of the Hf-EC, which implies that the decrease of EC is mainly associated to a strong decrease of electrical conductivity associated to the low frequency mechanism. (B) The test shown in figure was performed at constant strain rate but increasing the temperature during the test. The vertical lines separate portions of the experiment for which the temperature was constant. The rate of decrease of bulk EC increases significantly from 1373 to $1473 \mathrm{~K}$. In both the experiments once the stress was removed the bulk EC started to increase with a slow rate. Figure $5 \mathrm{C}$ and D show the resistivity spectra collected before ( $1^{\text {st }}$ trace) and after deformation (lowest recorded electrical conductivity during deformation) for sample 8B and 4B respectively. 
(A)
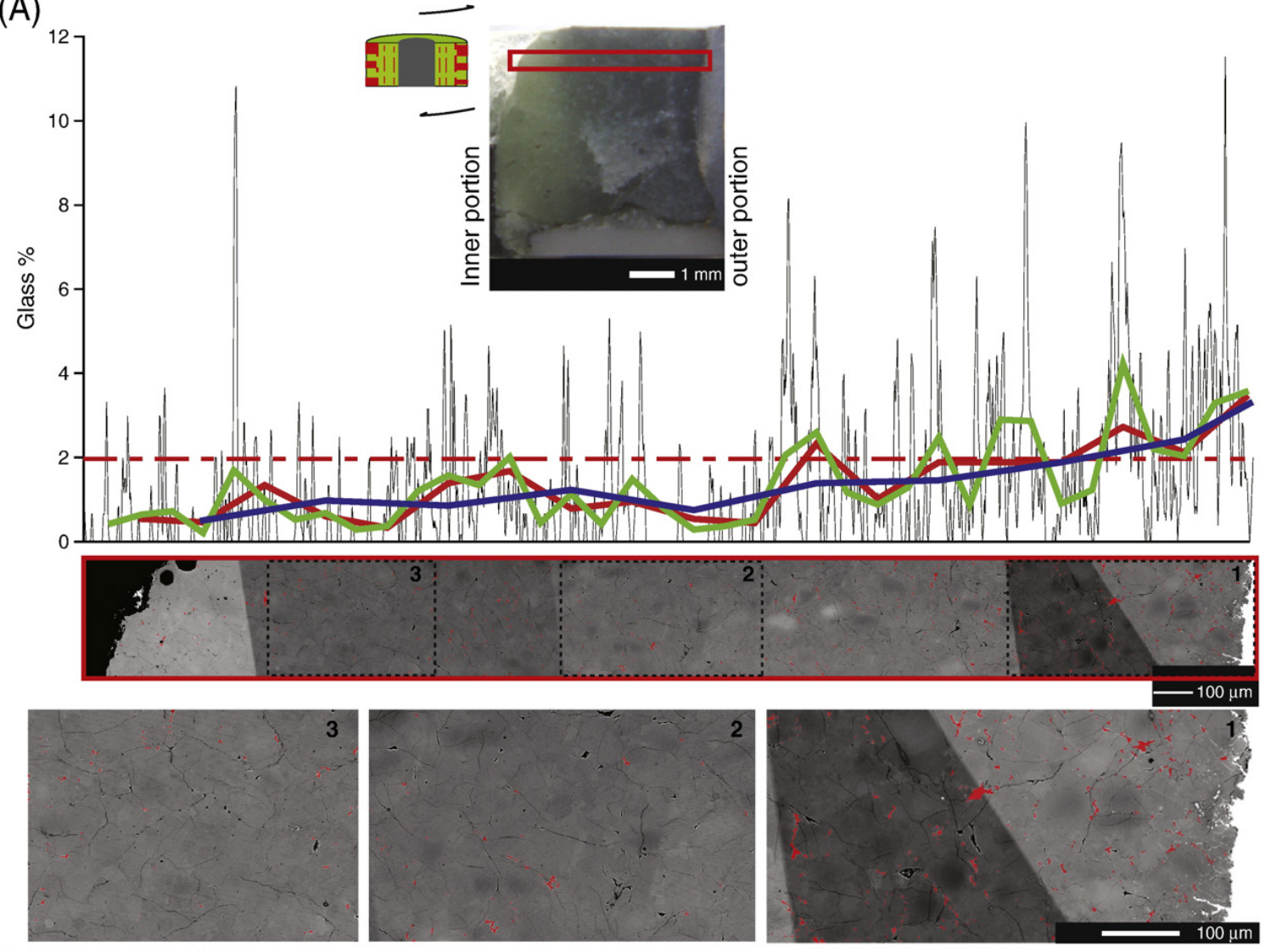

(B)
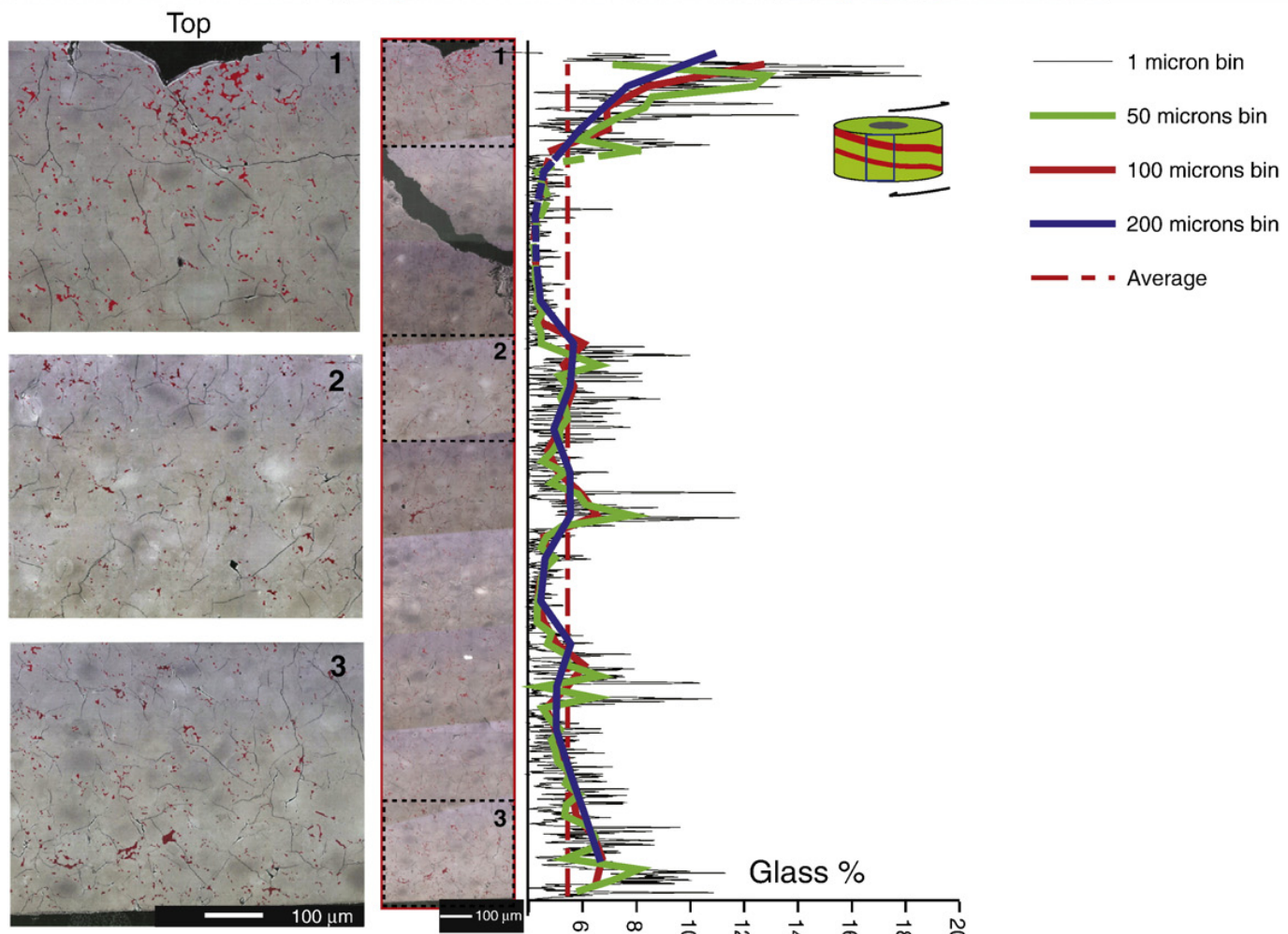

Bottom 
Figure 6: Back Scattered Electron (BSE) images and diagrams showing the distribution of glass (in red) in different sections of sample 8B. (A) Image analyses results for a collage of BSE images collected in the shear plane along the sample diameter. The picture shows the portion of sample where the BSE images were acquired. The different colours of the lines correspond to different bin sizes for the measurement of the glass percentage. At the bottom of the diagram the 3 pictures are enlargement of the entire section. Numbers and dashed lines indicate the magnified portions. (B) Same analyses and presentation of Figure 6A for a section cut on the outer portion of sample 8B along the sample axis. The sketch in the diagram illustrates the portion of sample where the images were collected. The dashed lines in the diagram are related to the presence of a large crack in the sample (formed during the quench), which altered the quantification of glass. 


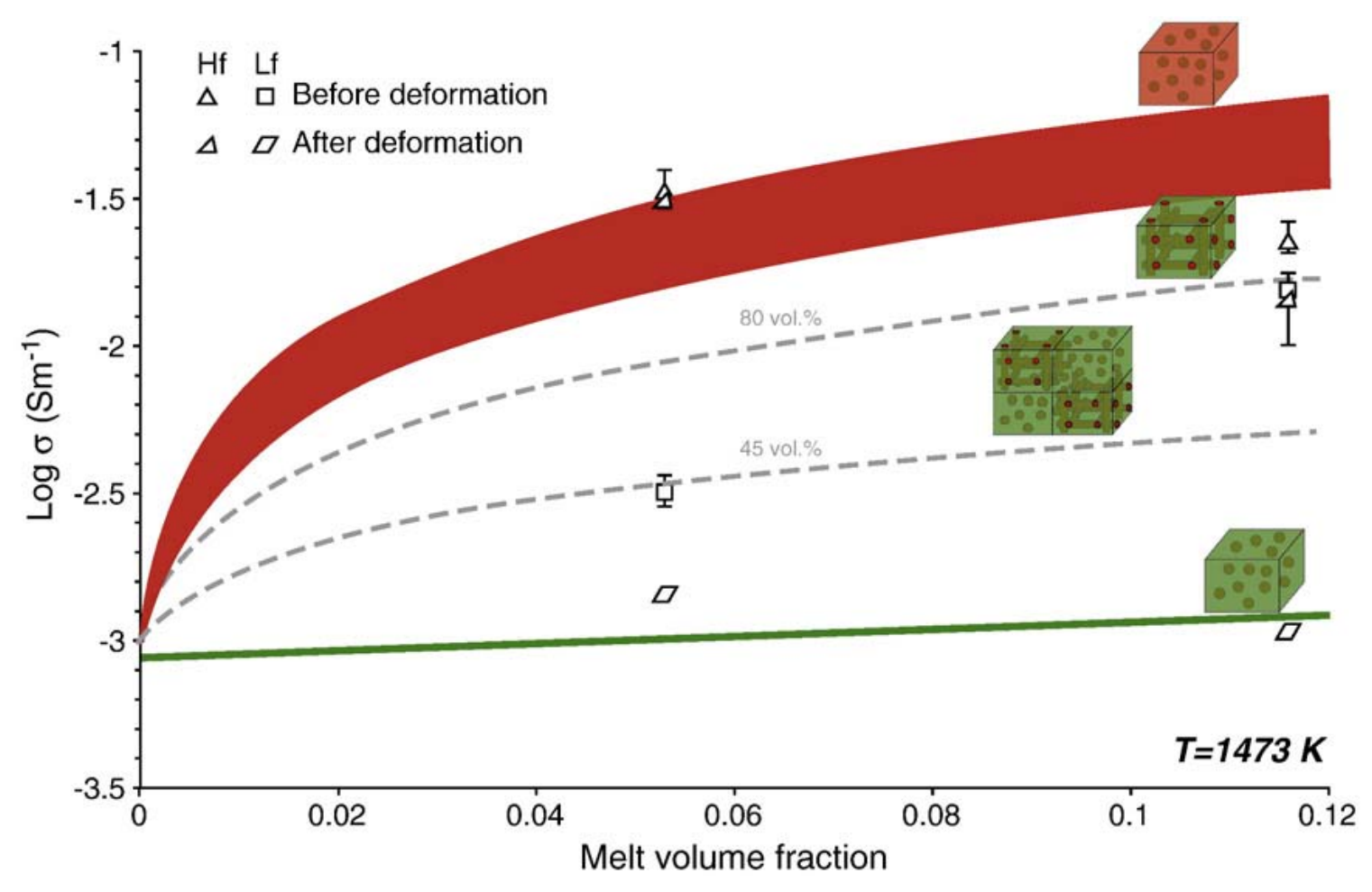

Figure 7: Logarithm of EC plotted as function of the melt volume fraction. The triangles and squares give the high and low frequency EC respectively, measured before deformation. The deformed triangles and squares give the EC after deformation in simple shear for the correspondent conduction mechanisms. The error bars give the range of EC obtained from different experiments. The light-red area gives the range of conductivities for a system in which all the melt is connected, in layers (highest values; Hashin and Shtrikman lower bound; (Hashin and Shtrikman, 1962) or in tubes (lower values). The green area represents the conductivity of olivine-basalt aggregates in which the melt is not connected (Hashin and Shtrikman lower bound; (Hashin and Shtrikman, 1962). The dashed grey lines give the conductivity for a system in which, only in part of the sample volume, the melt is connected (the volume of sample in which the melt is connected is given by the numbers close to the lines). These calculations have been performed using the Archie's law (see, ten Grotenhuis et al., 2005). All the calculations have been 
performed using data (measured at $400 \mathrm{MPa}$ ) from Constable and Duba (1990) for olivine and Pommier et al. (2010) for the basalt at $1473 \mathrm{~K}$. The sketches close to the coloured fields show the possible arrangements of melt (in red) and olivine (in green) for the different trends of variation of electrical conductivity. 


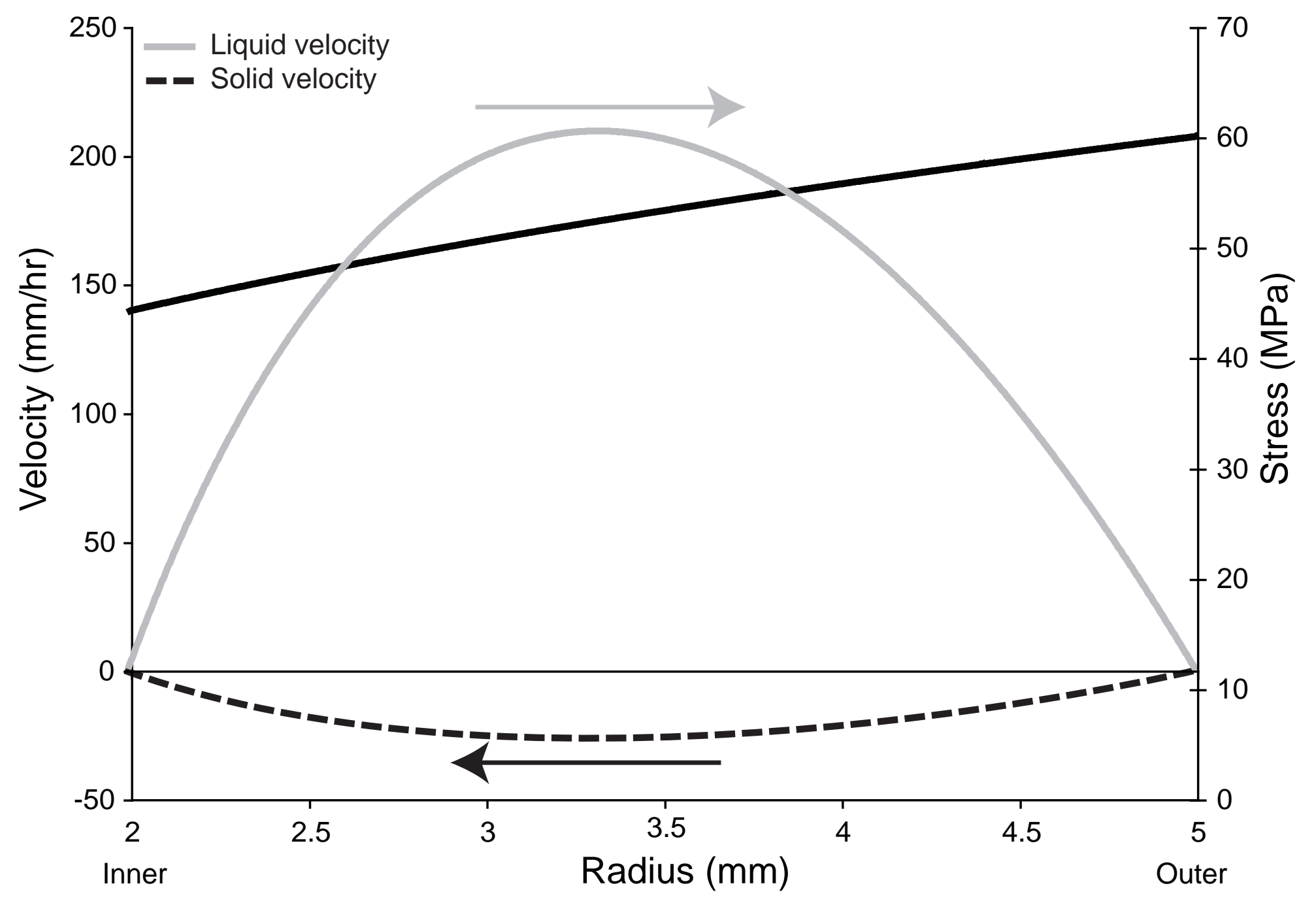

Figure 8 
Figure 8: Calculated solid (black dashed line) and liquid velocity (grey line) between the electrode and the outer portion of the samples deformed in torsional configuration. Positive velocities are for displacement toward positive values of the radius. The black continuous line gives the stress variation along the sample according to Paterson and Olgaard (2000). The calculations were performed with an isotropic viscosity of $10^{12} \mathrm{~Pa} \cdot \mathrm{s}$ (measured in the experiment on sample 8B), liquid viscosity of $80 \mathrm{~Pa} \cdot \mathrm{s}$ (Giordano et al., 2008), melt fraction (porosity) 0.116 (corresponding to 8wt.\% basalt), permeability $3.9 \cdot 10^{-15} \mathrm{~m}^{2}$ (calculated according to Holtzman et al. 2003). 


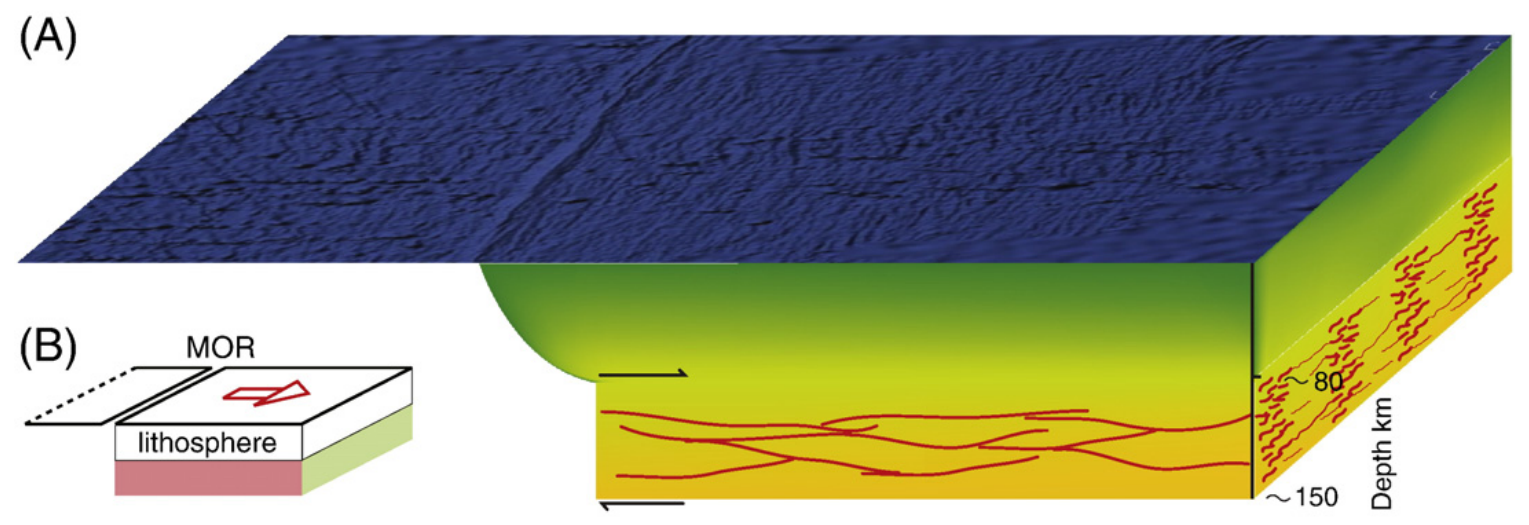

(C)

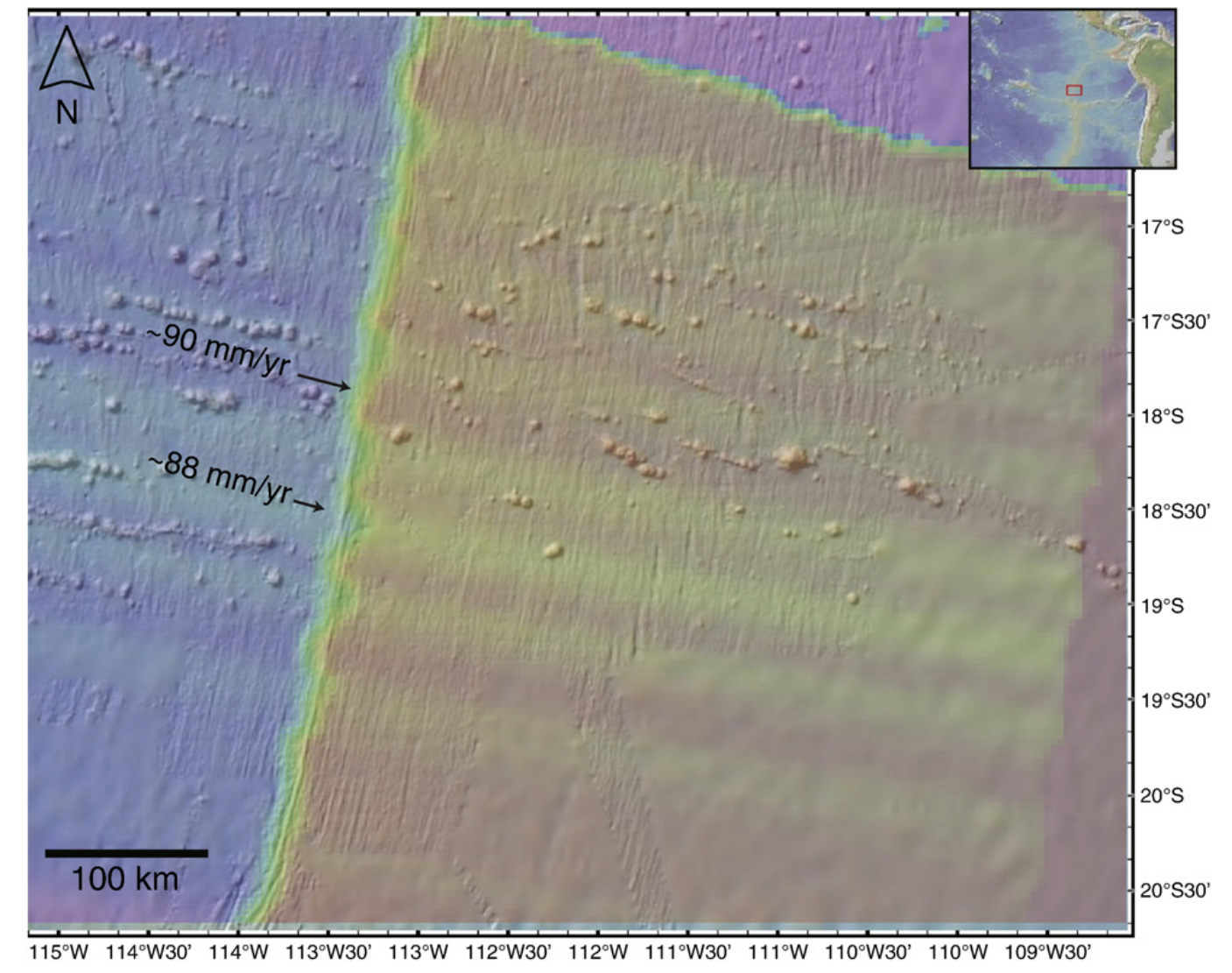

Figure 9: (A) Schematic illustration of the possible arrangement of melt at the LAB. The ocean floor picture is taken from Google Earth ${ }^{\circledR}$, in the region of the MELT experiment (e.g Baba et al. 2006). (B) Sketch of the lithosphere asthenosphere in the East Pacific Rise with the colours indicating the range of measured values of conductivity at the LAB

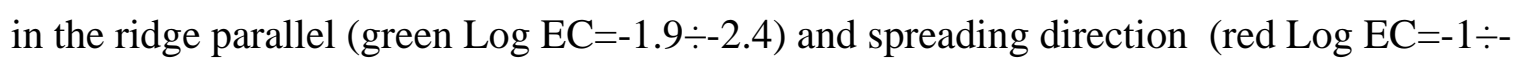
1.5). (C) Variations of spreading rates measured in the area of the MELT-experiment 
(Muller et al., 2008). From yellow to red the spreading rates vary from about $88 \mathrm{~mm} / \mathrm{yr}$ to $91 \mathrm{~mm} / \mathrm{yr}$. The map shows also the linear distribution of seamount. Their distribution in direction perpendicular to the ridge axis could mirror melt enrichment in the underlying portions of the LAB. 
Figure 10: Logarithm of the bulk EC as function of temperature (K). The continuous red line indicates the values of EC calculated as function of temperature for an olivine aggregate in which the 2 vol.\% of melt is fully connected (Hashin and Shtrikman upper bound; Hashin and Shtrikman, 1962). The dark green area shows the variation of conductivity as function of temperature for pure olivine and aggregates in which the melt (0.2 to 4 vol.\%) is not connected (Hashin and Strickman lower bound; Hashin and Shtrikman, 1962). The illustrations on the right hand side of the diagram are schemes of the two melt-configurations. The calculations have been performed using data (measured at $400 \mathrm{MPa}$ ) from Constable and Duba (1990) for olivine and Pommier et al. (2010) for the basalt. The light red and green areas indicate the values of EC measured in the spreading direction and in the ridge parallel direction during the MELT experiment respectively, as represented on the sketch at the bottom right hand side of the diagram (Baba et al. 2006; Evans et al., 2005). The square and deformed squares give the measured bulk EC before and after deformation respectively (see Tables 1 and 2 online material). 